\title{
Green synthesis of iron-based nanomaterials for environmental remediation: A review
}

\author{
Oladotun P. Bolade, Akan B. Williams, Nsikak U. Benson* \\ Department of Chemistry, College of Science and Technology, Km 10 Idiroko Road, Covenant University, Ota, Nigeria
}

\section{A R T I C L E I N F O}

\section{Keywords:}

Iron nanoparticles

Green synthesis

Environmental remediation

Eco-nanomaterials

Nanotechnology

\begin{abstract}
A B S T R A C T
The ever-increasing importance of green-based iron nanoparticles within the last decade and their environmental applications is a compelling reason to probe novel routes for their synthesis. Therefore, the principles of green chemistry, waste prevention, energy efficiency, safer solvents, and the benign precursor materials have become fundamental considerations in the synthesis process of these materials, birthing extensive study in this field. In this light, a comprehensive discussion of the successes of greener techniques and other biological nanotechnologies including the use of microorganisms (fungi, bacteria, actinomycetes, and viruses), algae, plant and their extracts for the synthesis of iron (Fe) nanoparticles (NPs) is presented. Although promising findings have been reported, substantial research gaps and the opportunity to capitalize on the emergence and rise of these eco-friendly sources have been identified. The application of synthesized nanoparticles for environmental remediation and their toxicological implications are also discussed.
\end{abstract}

\section{Introduction}

Nanotechnology is the ability to study and understand small particles (average size of $1-100 \mathrm{~nm}$ ) with large surface area. The word "Nano" is interpreted "dwarf" in Greek, which is $10^{-9} \mathrm{~m}$. Nobel laureate, Richard Feyman helped popularized the concept of nanotechnology in the $60 \mathrm{~s}$, although scientists had been using matter at nanoscale level unknowingly. The advent of electron microscopic techniques such as scanning electron and atomic force microscopies have enhanced synthesis and characterization of nanoparticles (Ahmed et al., 2014a,b).

Nanotechnology and iron nanomaterials have found wide applications in environmental remediation (Fang et al., 2018; Huang et al., 2018), drug delivery (Ivashchenko et al., 2017; Manatunga et al., 2017), electronics, biotechnology, catalysis (Arumugam et al., 2018; Isaad and El, 2018; Rethinasabapathy and Kang, 2017), cosmetics, space industry, cancer treatment and anticancer drug delivery (Allardvannier et al., 2017; Lin et al., 2017; Nosrati et al., 2018) and materials science. Nanotechnology is an emerging multi-disciplinary field connecting chemistry, physics, biology, material science, medicine (Kania et al., 2018), pharmacy and engineering. Nanoparticles have gained attention due to their unique morphological and physicochemical properties such as ultra-small size, shape (sheets, rods, tubes and wires), and size distribution. They also possess magnetic, optical, thermal and mechanical properties. Nanoparticles are generally classified as organic, also referred to as carbon-based nanomaterials and inorganic, which are mostly made of metals $(\mathrm{Ag}, \mathrm{Fe})$ and semiconductors $\left(\mathrm{TiO}_{2}\right)$. Several techniques have been proposed for the synthesis of nanoparticles generally classified as top-down and bottom-up approaches. Top-down methods such as grinding, etching, milling and machining involve breaking down of bulk material while bottom-up approach such as chemical reduction and sol-gel processes entail assemblage of smaller building blocks to form a larger structure - a process known as nanoparticle growth.

Physical and chemical syntheses of nanoparticles require the reaction of a precursor material with reducing agents such as sodium borohydride and hydrazine hydrate. These reducing agents are mostly toxic substances with hazardous effects on humans and the environment. This has necessitated research into biological methods involving the development of facile, greener and eco-friendly reducing agents for nanoparticles formation, resulting in the convergence of nanotechnology, environmental remediation and green chemistry. Researchers have reported the use of microorganisms such as bacteria, fungi and algae (Kaul et al., 2012; Subramaniyam et al., 2015), ionic liquids and eutectic solvents (Sanchez et al., 2018), bio- and agrowaste (Nisticò et al., 2018; Yang et al., 2018; Olajire et al., 2017a,b), plant materials such as leaves, fruit (Kumar et al., 2014; Mohan Kumar et al., 2013) and seed (Radini et al., 2018; Venkateswarlu et al., 2014),

\footnotetext{
* Corresponding author.

E-mail address: nsikak.benson@covenantuniversity.edu.ng (N.U. Benson).
} 


\section{Nomenclature}

AAS Atomic Absorption Spectroscopy

AFM Atomic force spectroscopy

CTAB Cetyltrimethylammonium bromide

DRS Diffuse reflection spectroscopy

EDS Energy dispersive spectroscopy

Fe-NPs Iron nanoparticles

FESEM Field emission scanning electron microscopy

FT-IR Fourier-transform infrared

FRAP Ferric reducing antioxidant power
HR-SEM High resolution scanning electron microscopy

ISCO in situ chemical oxidation

MIONPs Magnetic iron oxide nanoparticles

MOFs metal organic frameworks

NPs Nanoparticles

PL Photoluminescence

SEM-EDX Scanning electron microscopy- Energy dispersive X-ray

TEM Transmission electron microscopy

VSM Vibrating sample magnetometer

XRD X-ray diffraction microwave heating (Alvarez-romero et al., 2018; Liang et al., 2017; Kombaiah et al., 2018a), and biodegradable polymers as greener routes for the synthesis of various nanoparticles. Other green-based methods for green synthesis of iron nanoparticles reported include amino acids (Marimón-Bolívar and González, 2018), vitamins, enzymes and waste (Wei et al., 2016a). Energy use, cost, environmental friendliness and availability are important considerations in adopting a greener technique. Biosynthesized nanoparticles often display lower toxicity, agglomeration and improved stability in comparison with those prepared using physical and chemical methods. This is due to the stabilizing and capping effect of bioactive components of these biological materials, particularly plants.

Iron nanoparticles - metallic, bimetallic, trimetallic and oxides, have been widely reported as promising agents for environmental remediation (Sharma et al., 2018). There are sixteen different known iron oxides (Wu et al., 2015). They possess antimicrobial properties and have been applied for degradation of dyes (via adsorption process) (Sharma et al., 2017a,b), nitrobenzenes, antibiotics (Stan et al., 2017), wastewater treatment (Fazlzadeh et al., 2018), removal of metal contaminants and as heterogeneous catalysts (Mondal and Purkait, 2018) in environmental processes. The emergence of iron nanoparticles for remediation is due to magnetic susceptibility, non-toxicity and dual redox capability on reaction with water. Furthermore, it possesses large surface area and high reactivity.

Several iron nanoparticles such as biosynthesized zerovalent iron (Soliemanzadeh and Fekri, 2017a), magnetic iron oxide nanoparticles, bimetallic nanoparticles (Luo et al., 2016), trimetallic nanoparticles (Basavegowda et al., 2017; Mishra et al., 2015) and copper ferrite nanoparticles (Kombaiah et al., 2018a) have been reported. Carbon-, starch-, biopolymer-, and clay mineral - supported nanocomposites (Abujaber et al., 2018; Ghaedi \& Arabi, 2018; Krishna et al., 2016; Ostovan et al., 2018; Soliemanzadeh and Fekri, 2017b; Wang et al., 2015) as well as magnetic core-shell silica and amino functionalized nanoparticles (Mahmoud et al., 2016b; Farzad and Veisi, 2017) have been designed to mitigate particle agglomeration and enhance dispersion. Buds, fruits, seeds, stems and leaf extracts of several plants such as Clove (Afsheen et al., 2018), Lantana camera (Rajiv et al., 2017a), Citrus maxima (Li et al., 2018), Azardirachta Indica (Bolade et al., 2018; Devatha et al., 2018), green tea (Zhu et al., 2018), eucalyptus (Weng et al., 2017), Rosa damascene, Thymus vulgaris, and Urtica dioica

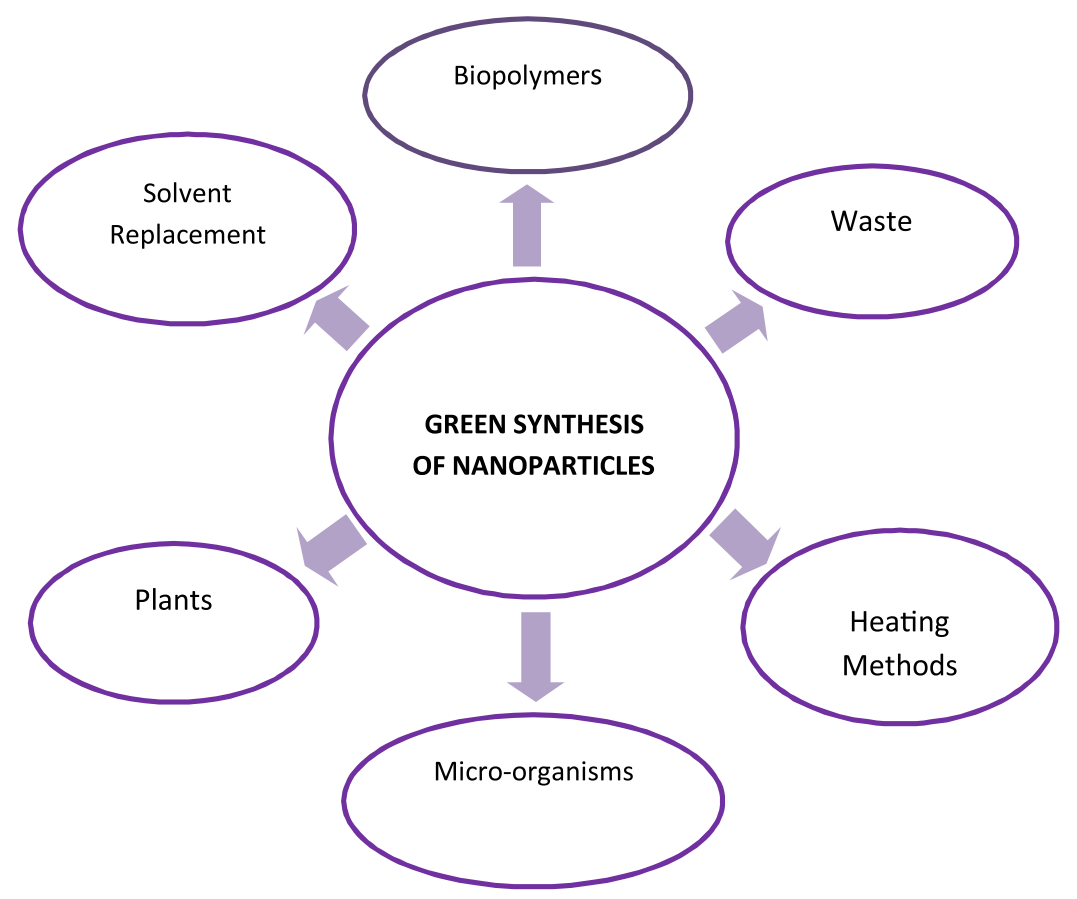

Fig. 1. Illustration of greener routes for synthesis of iron nanoparticles. 
(Fazlzadeh et al., 2017), Cymbopogon citratus (Bolade et al., 2018), and Canna indica (Bolade et al., 2019) have been utilized as bioreducing agents for nanoparticles synthesis. Furthermore, waste materials such as banana peel and citrus juice waste have been employed (Machado et al., 2014).

\subsection{Green-based synthesis of iron nanoparticles}

In line with the principles of green chemistry (Anastas and Werner, 1998), an efficient greener route to nanoparticle synthesis will employ renewable energy, minimize waste and reduce energy use. The conceptual development of methodologies for eco-friendly biosynthesis of nanoparticles is presented in Fig. 1. Consequently, numerous studies within the last decade have reported the use of water as solvent with bioactive components of plants as capping and stabilizing agents in the synthesis of nanoparticles. Leaves and fruits of green plants have been recently studied for the eco-friendly synthesis of iron nanoparticles using iron (II) or iron (III) chloride solutions as precursor (Bolade et al., 2018). This is possible because these plants contain bioactive components, mostly polyphenols that act as reducing and capping agents. Aquatic and terrestrial weeds have also been used (Prabhakar and Samadder, 2017). The ability to synthesize nanoparticles in aqueous media and under standard conditions (temperature and pressure) reduces the production of toxic by-products and disposal of organic waste/reagents.

In comparison with conventional heating techniques, microwave heating facilitates lower energy use leading to nanoparticle formation within a fraction of the time required for conventional methods. Also, prokaryotic and eukaryotic organisms such as actinomycetes, yeast, fungi and algae facilitate intracellular and extracellular formation of nanoparticles at near ambient temperature and neutral $\mathrm{pH}$. Extensive reviews on the design and applications of different nanomaterials guided by the principles of green chemistry have been reported (Adil et al., 2014; Fawcett et al., 2017; Gilbertson et al., 2015; Saratale et al., 2017; Schröfel et al., 2014; Shukla and Iravani, 2017; Thakur et al., 2014; Zhang et al., 2016). Further reviews written within the past few years on greener synthesis and characterization of nanoparticles abound (Hulkoti and Taranath, 2014; Łuczak et al., 2016b; Kharissova et al., 2013; Sharma et al., 2017b). Synthesis and applications of metal and metal oxide nanoparticles - particularly iron, silver and zinc oxide, in environmental studies are widely reported (Abdelghany et al., 2017; Ahmed et al., 2017, 2016; Iqbal et al., 2017; Saif et al., 2016; Rauwel et al., 2015).

The review presented herein explores different greener techniques for the synthesis of iron-based nanoparticles. In particular, biosynthesis using green plants and microorganisms, the use of ionic liquids as a replacement for molecular solvents, which are mostly toxic organic liquids or water, and microwave-assisted synthesis are reviewed. While nanoparticles have found diverse applications in different fields, their applications for biosorption of metals, degradation of dyes and other organic contaminants (Lin et al., 2018) and as catalysts in organic and environmental processes are discussed. In addition to reviewing the syntheses and applications of iron nanoparticles, the toxicological effects of these materials are briefly discussed and some critical challenges are identified that may inspire future research drive.

\section{Microorganism-based synthesis of iron nanoparticles}

Microorganism-based synthesis of nanoparticles has gained attention in the past few decades due to its benefits over conventional chemical syntheses (Table 1). These advantages include synthesis at room temperature - an energy efficient process, consumption/production of less toxic chemicals/by-products, natural abundance, ease of scale up and ability to cope in extreme conditions (Park et al., 2016). Microorganisms such as fungi, bacteria and yeast can synthesize nanoparticles via extracellular or intracellular mechanism. These processes

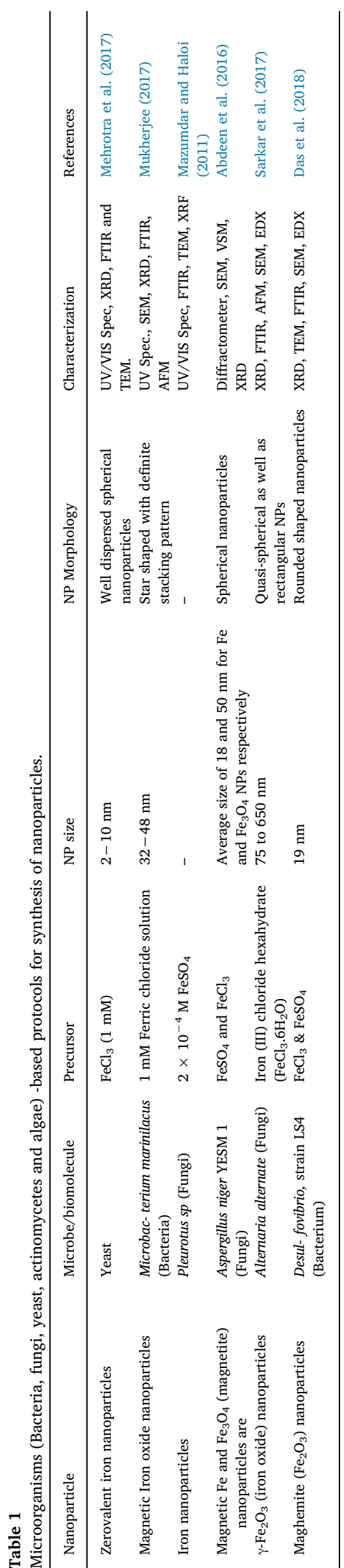


entail the enzymatic reduction of metal ions, producing well dispersed nanoparticles with small size distribution, with proteins, peptides and genes acting as natural capping agents, which in turn provide stability and reduce agglomeration of nanoparticles (Singh et al., 2016). Unlike in extracellular mechanism, which involves enzymatic reduction of metal ions bound to the cell wall/surface of microorganism electrostatically, the metal ions diffuse into the cell where they react with enzymes to form nanoparticles in intracellular mechanism.

Mukherjee (2017) reported the formation of magnetic iron oxide nanoparticles of 32-48 nm average particle size using cultured strains of Microbacterium marinilacus isolated from sediment samples collected from Damodar River in India. $1 \mathrm{mM}$ of the precursor solution (ferric chloride solution) was added to the isolated bacterium and incubated resulting in the formation of nanoparticles marked by a colour change of the culture from light brown to dark brown within $2 \mathrm{~h}$. In order to separate the synthesized nanoparticles from cells, the culture was centrifuged, the supernatant separated, dehydrated and characterized using scanning electron microscopy. Pleurotus sp. a filamentous fungus was utilized to synthesize iron nanoparticles (Mazumdar and Haloi, 2011). The test fungus was grown over seven days and fast-growing mycelium was isolated, cultured and incubated for $96 \mathrm{~h}$ at $28{ }^{\circ} \mathrm{C}$. This was followed by centrifugation to separate settled mycelia from culture broth. Ferrous sulphate solution was then mixed with $1 \mathrm{~g}$ of washed mycelia and shaken for $72 \mathrm{~h}$. Nanoparticles formed were characterized using Transmission electron microscopy (TEM), Scanning electron microscopy (SEM), and Fourier-transform infrared spectroscopy (FTIR).

Abdeen et al. (2016) have reported the fungi-based intracellular synthesis of magnetic iron and magnetite nanoparticles using Asperigillus niger isolated and cultured over 7 days. According to literature, about $250 \mathrm{mg} / \mathrm{mL}$ homogenized mycelia was mixed with precursor salts $\left(\mathrm{FeSO}_{4}\right.$ and $\mathrm{FeCl}_{3}$ ), incubated for 6 days, centrifuged and dried to obtain $\mathrm{FeS}$ and $\mathrm{Fe}_{2} \mathrm{O}_{3}$ pellets. The pellets were washed, dried and subjected to supercritical conditions by heating liquid ethanol to $300{ }^{\circ} \mathrm{C}$ at $850 \mathrm{psi}$ for one hour, then left to cool. This is a green approach as it avoids the direct use of organic solvents in liquid state in the synthesis of nanoparticles. Characterization of nanoparticles was carried out using SEM and XRD. A schematic diagram showing this process is presented in Fig. 2.

Extracellular synthesis of iron oxide nanoparticles using Alternaria alternate, a phytopathogenic fungus has been reported (Sarkar et al., 2017). The filtrate of cultured fungus was employed as reducing agent with iron (III) chloride solution as the precursor at $30{ }^{\circ} \mathrm{C}$ for $24 \mathrm{~h}$,
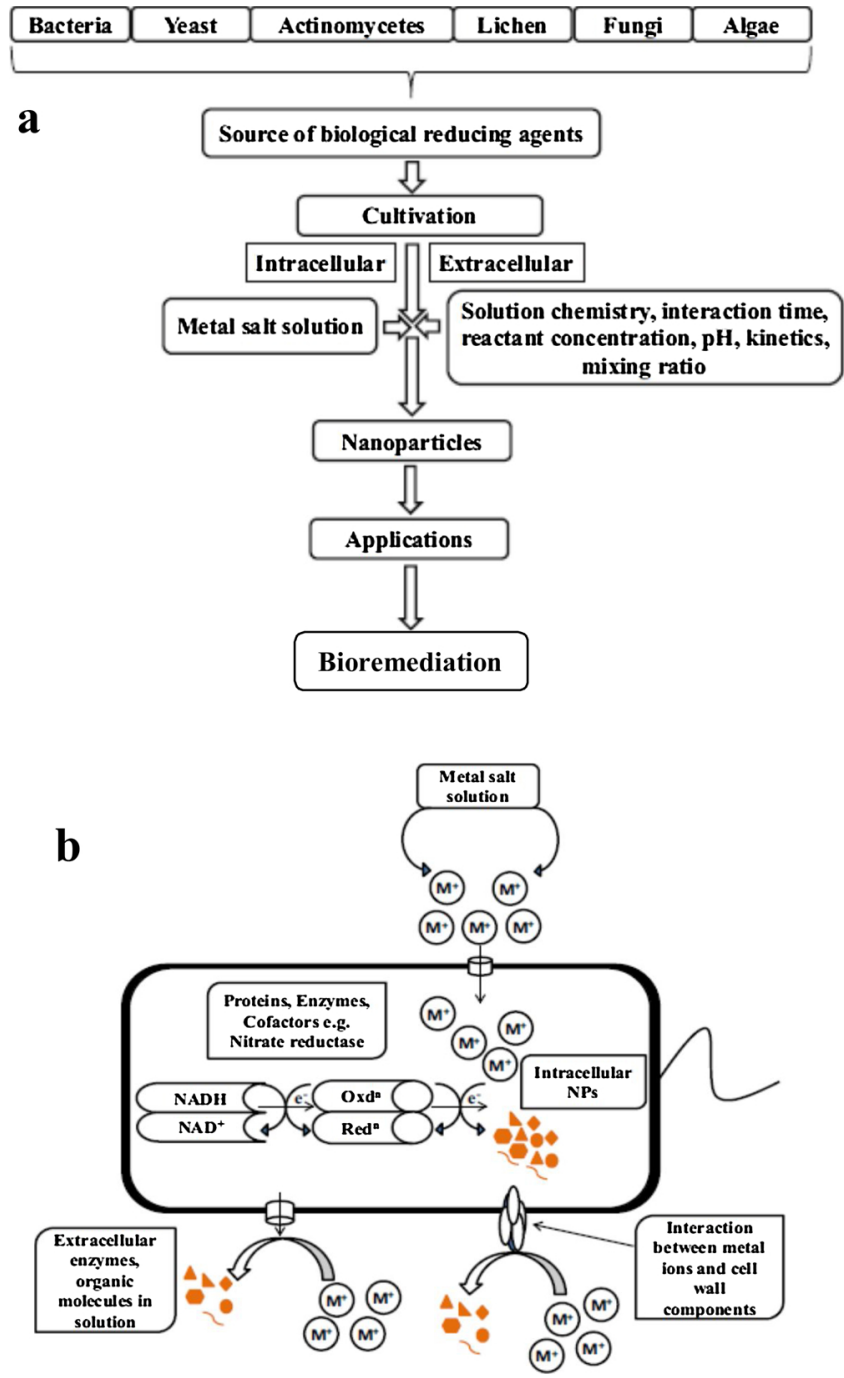

Fig. 3. (a) Microbial synthesis of nanoparticles. Modified from (Salunke et al., 2016). (b): Schematic illustration of the microbial synthesis of nanoparticles (Salunke et al., 2016).

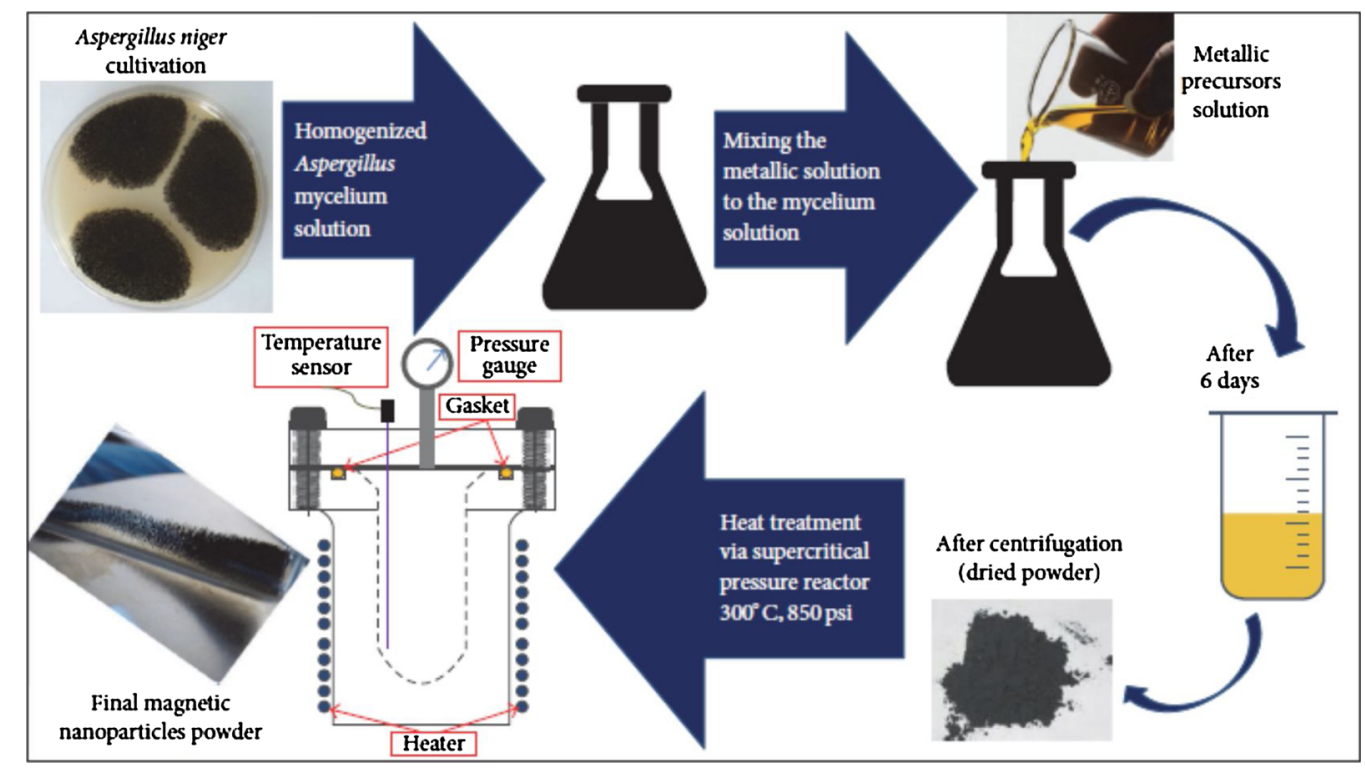

Fig. 2. Schematic diagram of the biological-physical method for synthesis of magnetic nanoparticles (Abdeen et al., 2016). 


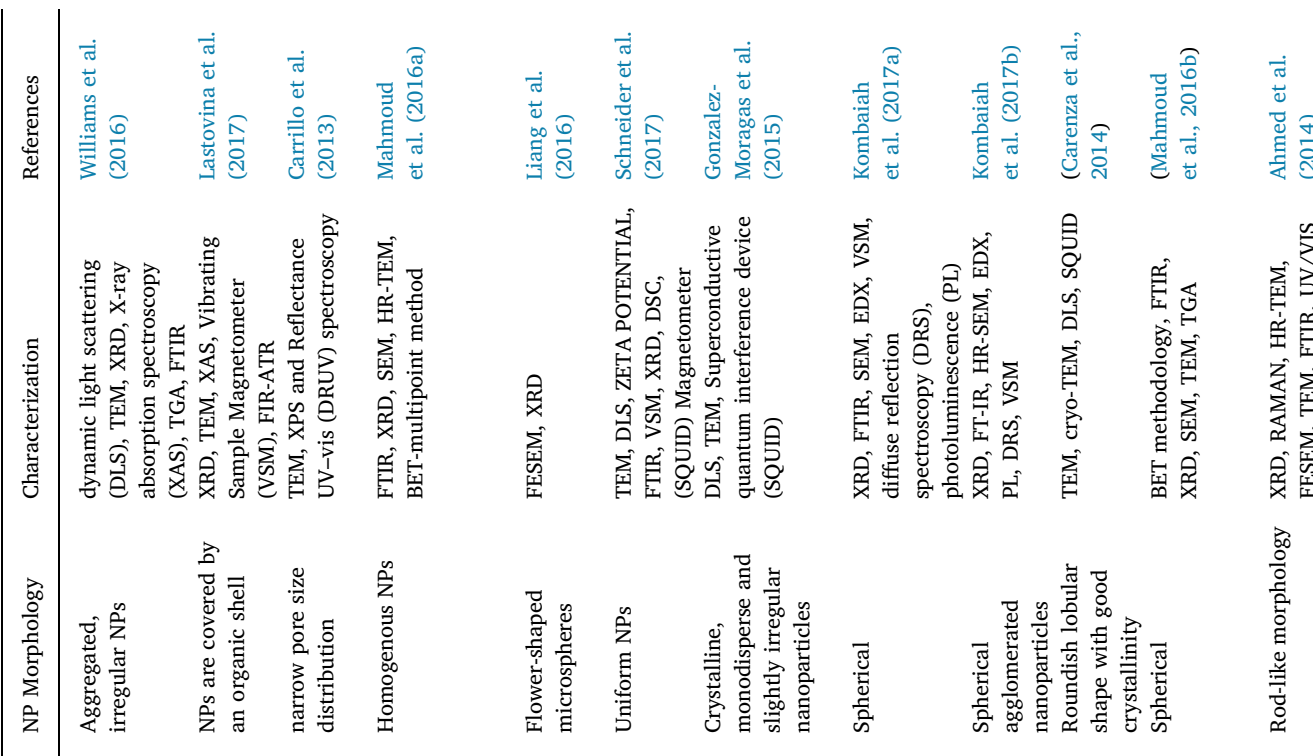

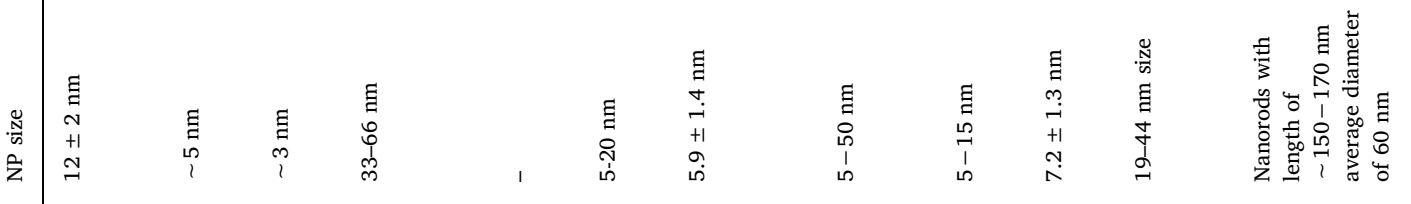

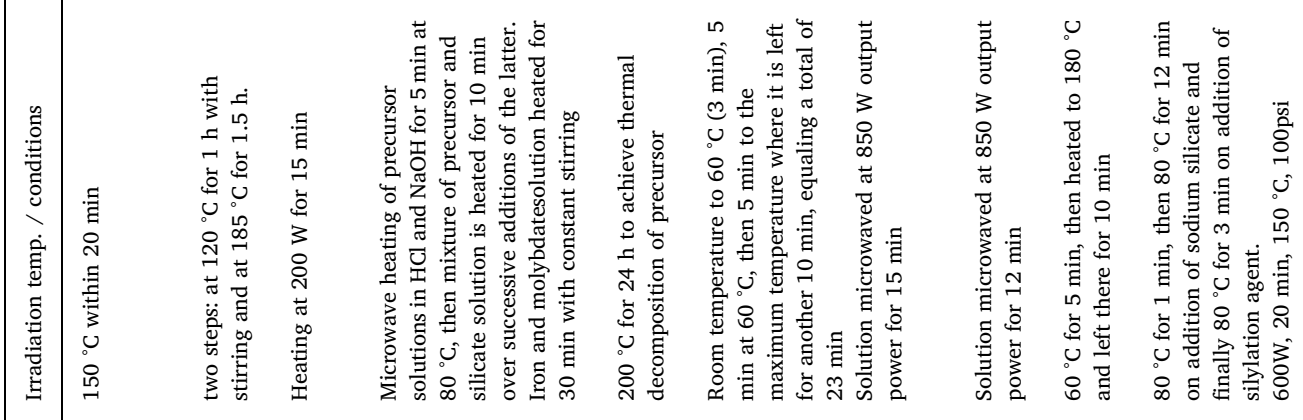

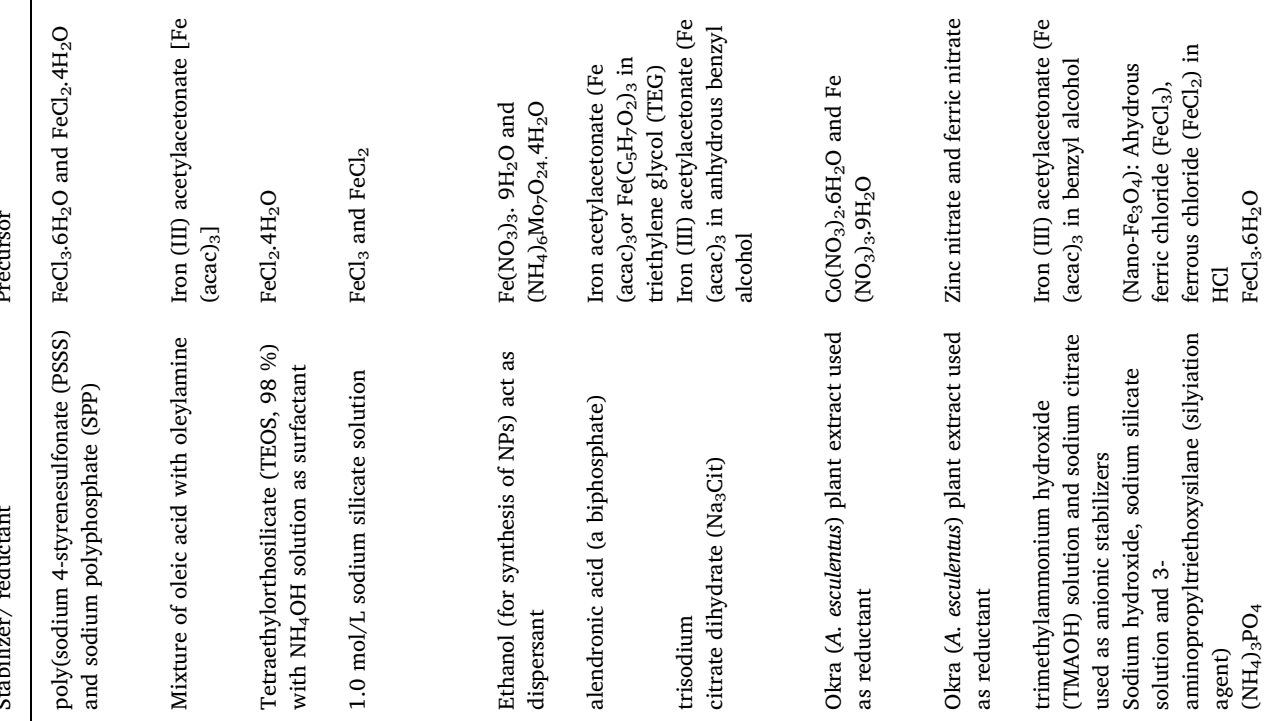

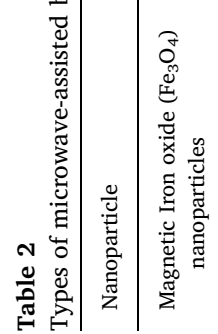

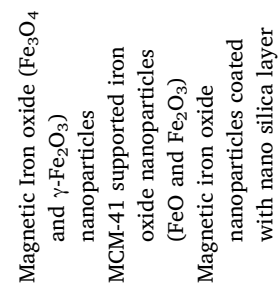

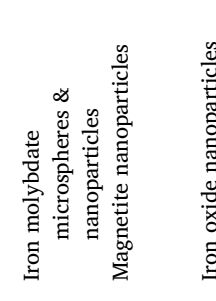

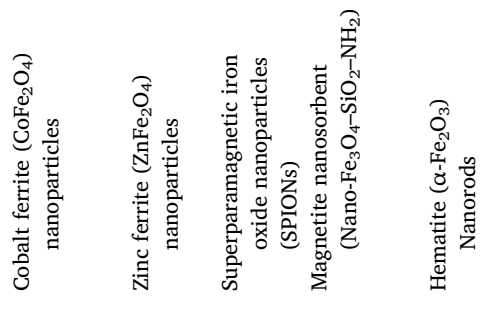


resulting in the synthesis of iron oxide nanoparticles - marked by change in colour from yellow to dark brown. Synthesized nanoparticles were separated by centrifugation, washed and characterized using Transmission electron microscopy (TEM), Atomic force spectroscopy (AFM), Fourier-transform infrared spectroscopy (FTIR), and X-ray diffraction (XRD). Das et al. (2018) anaerobically synthesized maghemite nanoparticles with average particle size of $18 \mathrm{~nm}$ using native hypersaline sulphate reducing bacteria isolated and cultured from sediment of saltpan, Goa, India. Ferric chloride and Ferrous sulphate were used as nanoparticle precursors under anoxic conditions via nitrogen purging and incubated over a thirty-five-day period. Nanoparticles formed - evidenced by the appearance of dark black colouration - were collected by centrifugation and characterized with XRD, TEM, FTIR, SEM and EDX. A further study on developmental toxicity of Zebra fish was carried out. Yeast-based synthesis of zerovalent iron nanoparticles has been reported (Mehrotra et al., 2017). The use of microorganisms as effective route for the biosynthesis of metal nanoparticles has been reported (Salunke et al., 2016) (Fig. 3a,b).

\section{Microwave-assisted synthesis of nanoparticles}

Microwave-assisted synthesis involves electromagnetic irradiation of precursor solvents and reducing agents via ionic conduction and molecular motion. This is achieved by high temperature heating directly inside the sample (Łuczak et al., 2016b). Microwave irradiation facilitates greener and rapid heating during the preparation of nanoparticles due to lower energy requirements. Additionally, it promotes uniform dispersion of ultra-small nanoparticles with accelerated nucleation and digestive ripening. Heating methods that can achieve preparation of nanoparticles within minutes with appreciable degree of control over nanoparticle size, dispersion and crystallinity are imperative to greener synthesis techniques (Amores et al., 2016; Ortega et al., 2015). Several microwave-assisted biosynthesis of iron-based nanoparticles have been developed and reported (Table 2). Comparing microwave synthesis with other thermal decomposition methods, Kombaiah et al. (2017a) showed that microwave technique was considerably more efficient and economical in terms of energy consumption and cost of fabrication during synthesis of nanoparticles.
Schneider et al. (2017) described the fast and green microwave synthesis of magnetic nanoparticles and their coating with alendronic acid, a reactive biphosphate. Uniform nanoparticles with small particle size were synthesized with microwave heating at $200{ }^{\circ} \mathrm{C}$ while iron acetylacetonate in triehtylene glycol, TEG, served as precursor solution. The choice of TEG - a greener solvent, is due to its low isoelectric point, non-toxicity, high viscosity and high boiling point, which makes it amenable to solvothermal decomposition. The reaction was conducted under inert conditions achieved with nitrogen gas, $\mathrm{N}_{2}$.

In order to overcome the challenge of low nanoparticles yield due to limited size of reaction vessel, which is a major drawback for large scale application of microwave-assisted synthesis, Gonzalez-Moragas et al. (2015) have described a scale-up method for the synthesis of multigram iron oxide nanoparticles using a multi-mode microwave unit. To begin with, laboratory-scale synthesis of nanoparticles was carried out with Iron (III) acetylacetonate $\left(\mathrm{Fe}(\mathrm{acac})_{3}\right.$ in anhydrous benzyl alcohol as precursor. Temperature ramping was applied from room temperature to $180{ }^{\circ} \mathrm{C}$ over $20 \mathrm{~min}$ and cooled within $3 \mathrm{~min}$ at $300 \mathrm{~W}$. DLS and TEM characterization of synthesized nanoparticles revealed average particle size of $3.8 \pm 0.8 \mathrm{~nm}$. Ten-fold scale up was then carried out under optimized conditions with higher microwave power of $500 \mathrm{~W}$, higher maximum heating temperature $\left(200{ }^{\circ} \mathrm{C}\right)$ and extended reaction time. Excellent yield $>80 \%$ was achieved using the scale-up method.

Li et al. (2016) successfully prepared a magnetically recoverable nanocatalyst by grafting silver nanoparticles on carboxymethyl cellulose support under microwave irradiation and subsequently incorporating magnetic iron oxide nanoparticles into it for the degradation of catalyzed hydrogenation of carbonyls to carboxylic acids in water (Fig. 4).

Williams et al. (2016) have reported the synthesis of polymersupported multifunctional magnetite nanoparticles via microwave heating method at $150{ }^{\circ} \mathrm{C}$ for $20 \mathrm{~min}$. In a single step, aggregated nanoparticles with high crystallinity and aqueous stability were prepared using $\mathrm{FeCl}_{3} \cdot 6 \mathrm{H}_{2} \mathrm{O}$ and $\mathrm{FeCl}_{2} \cdot 4 \mathrm{H}_{2} \mathrm{O}$ as precursors. Lastovina et al. (2017) showed that a two-step microwave heating process can be applied for the synthesis of magnetite and maghemite nanoparticles

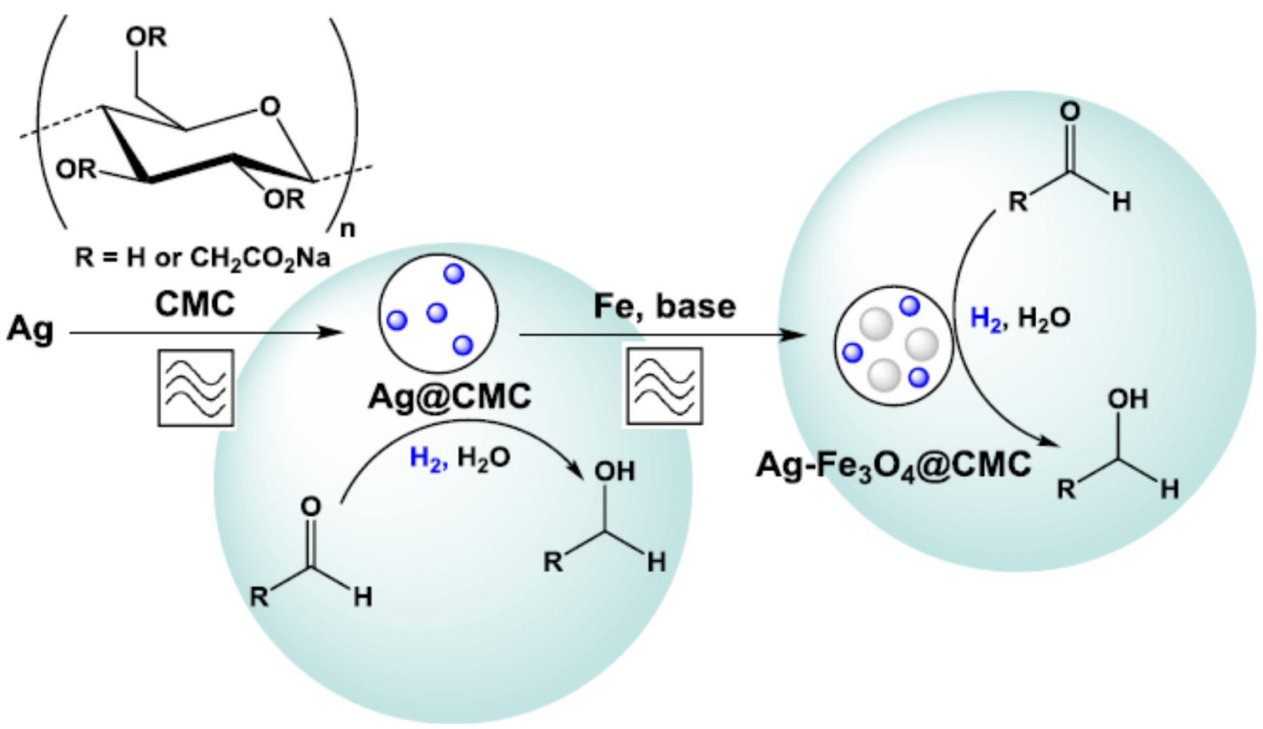

Fig. 4. Schematic diagram for synthesis of magnetic Ag- $\mathrm{Fe}_{3} \mathrm{O}_{4} @ \mathrm{CMC}$ (Li et al., 2016). 


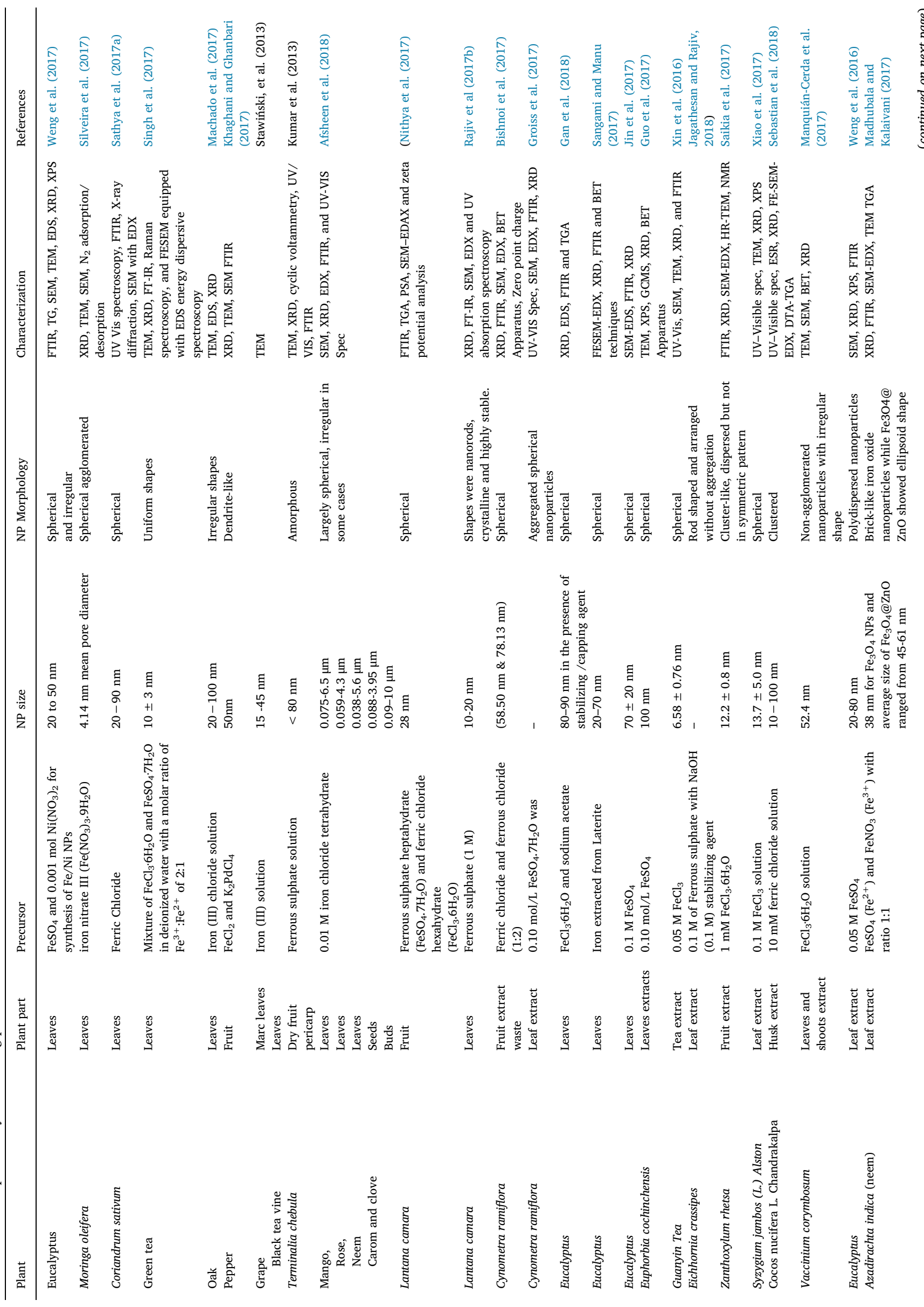


with iron (III) acetylacetonate dissolved in a mixture of oleic acid and oleylamine. Different ratios of both stabilizers synthesized nanoparticles with average particle size of $5 \mathrm{~nm}$ by heating at $120^{\circ} \mathrm{C}$ for $1 \mathrm{~h}$ with stirring and at $185^{\circ} \mathrm{C}$ for $1.5 \mathrm{~h}$. The stabilizers effectively reduced agglomeration of nanoparticles formed, with oleic acid having greater effect.

The combination of microwave and with other synthesis techniques such as hydrothermal and solvothermal methods have been reported (Grindi et al., 2018). This has the advantage of extremely fast heating rate at high temperature (both in polar solvents and non-polar solvents such as hexane), which is favourable for preparation of nanoparticles with high crystallinity (Liang et al., 2017). Grindi et al. (2018) reported the one-pot synthesis of strontium hexaferrite nanoparticles via microwave-assisted hydrothermal technique with Iron (III) nitrate nonahydrate and strontium nitrate as precusors. After varying microwave temperature and heating rate, optimum irradiation condition was achieved at $200{ }^{\circ} \mathrm{C}$ and heating rate $25{ }^{\circ} \mathrm{C} / \mathrm{min}$ for one hour. In comparison with classical hydrothermal process, microwave-assisted irradiation achieved nanoparticle synthesis without crystallization of hematite (due to high heating rate) and in shorter time.

Microwave-assisted techniques present a viable route to incorporating nanoparticles on the surface or within the framework of polymeric supports as a way of enhancing dispersion and stability of nanoparticles, which several unsupported nanoparticles can hardly achieve (Mahmoud et al., 2016a). Also, Carrillo et al. (2013) reported the loading of iron oxide nanoparticles on the surface of MCM-41 silica support. Silica material, helical mesoporous silica and well-ordered silica spheres with core shell structure were prepared from tetraethylorthosilicate and ammonium hydroxide solution surfactant by varying compositional ratios. Iron oxide nanoparticles, synthesized from $\mathrm{FeCl}_{2} \cdot 4 \mathrm{H}_{2} \mathrm{O}$ precusor was microwave-coated on silica supports by heating mixture of precusor and silica supports at $200 \mathrm{~W}$ for $15 \mathrm{~min}$. Characterization with XRD spectroscopy showed silica supported iron oxide nanoparticles with average pore diameter of $3 \mathrm{~nm}$. Microwaveassisted biosynthesis of iron-based ceramic nanoparticles - whereby plant extracts are utilized as reducing agent, have been carried out and compared with conventional heating methods (Kombaiah et al., 2017a, b). Both studies reported the synthesis of agglomerated, spherical cobalt-and zinc ferrite nanoparticles respectively with okra plant extract as reducing agent. Characterization was carried out using EDX, FT-IR, $\mathrm{XRD}$, high resolution scanning electron microscopy (HR-SEM), photoluminescence (PL), diffuse reflection spectroscopy (DRS), and vibrating sample magnetometer (VSM). Nanoparticles synthesized by conventional and microwave heating methods exhibited different morphological and magnetic properties, with microwave-synthesized particles having better optical and magnetic properties and smaller average diameter.

\section{Plant-mediated synthesis}

The process of synthesizing zerovalent iron nanoparticles using plant materials such as leaves, stems or back relies upon the successful extraction of bioactive components of the plant materials. These compounds include polyphenols, saponins, organic acids, vitamins and polysaccharides, which are soluble in water and some organic solvents such as methanol and acetone. Subsequently, they act as capping and reducing agents when reacted with a precursor, mostly iron (III) chloride solution. The reduction of $\mathrm{Fe}^{3+}$ to $\mathrm{Fe}^{0}$ results in the formation of zerovalent ion nanoparticles. A summary of plant-based procedures for the synthesis of nanoparticles is provided in Table 3. 
<smiles>O=c1cc(-c2ccc(O)c(O)c2)oc2cc(O)cc(O)c12</smiles>

Polyphenolic compound<smiles>O=C1O[C@H]([C@H](O)CO)C(O)=C1O</smiles>

Ascorbic acid

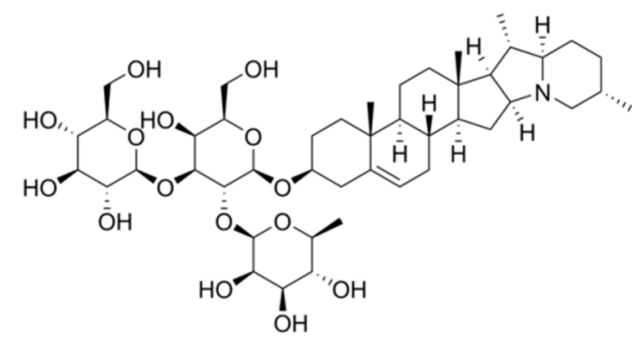

Saponin
Xiao et al. (2016) have carried out studies using fifteen plant species obtained in China to understand the influence of the major bioactive components of these plants on iron reduction during synthesis of zerovalent ion nanoparticles. Iron nanoparticles were synthesized by boiling powdered plant leaves with deionized water and heating for one hour to extract biomolecules, thereafter, the extract obtained was reacted with iron (III) chloride as precursor. Morphology and particle size determination of the synthesized nanoparticles was carried out using TEM and XRD while FTIR was employed to identify likely active functional groups. Uniform, spherical nanoparticles with average size of $5 \mathrm{~nm}$ were obtained (Table 3 ). FTIR spectra of plant extracts before and after reaction with precursor solution were obtained to understand the variation in composition of biomolecules. Of the biomolecules investigated, namely polyphenols, reducing sugars, flavonoids and proteins, they established that polyphenol was the most active molecule in the reduction of $\mathrm{Fe}^{3+}$ during nanoparticle synthesis. Extracts obtained from S. jambos (L.) Alston and D. longan Lour showed stronger ability to reduce $\mathrm{Fe}^{3+}$ than other plants and better capacity to remove hexavalent chromium from solution, with S. jambos (L.) Alston showing $100 \%$ removal efficiency within $60 \mathrm{~min}$ (Xiao et al., 2016).

During synthesis of nanoparticles, several conditions have to be optimized such as temperature, solution $\mathrm{pH}$, ratios of plant material mass:volume of extracting solvent and volume of plant extract:precursor solution. Huang et al. (2015) studied the factors that account for the reactivity of green-synthesized iron nanoparticles for the degradation of malachite green, a dye. Nanoparticles were synthesized from green tea leaves with iron (II) sulphate as precursor solution. To understand the optimum conditions affecting the synthesis of nanoparticles, there was variation in volume of tea extract reacted with iron (II) solution at different temperatures and $\mathrm{pH}$. Synthesized nanoparticles were applied for degradation of malachite green to observe their reactivity at varying conditions. The efficiency of nanoparticles in removing malachite green decreased with increase in leaf extracts, with corresponding increase in particle size due to agglomeration. Also, increase in $\mathrm{pH}$ resulted in reduced degradation of malachite green. This can be accounted for by ionization and precipitation effects at basic $\mathrm{pH}$. Furthermore, increase in temperature led to increase in nanoparticle reactivity, although this could stimulate agglomeration due to reduced capping ability of bioactive components at high temperatures. Over 90 $\%$ degradation of malachite green dye was achieved with ratio of precursor:tea extracts of 1:1, pH 6 and temperature of $318 \mathrm{~K}$. Bishnoi et al. (2017) successfully separated green synthesized magnetic iron oxide nanoparticles via an external magnetic field. Separated nanoparticles were then washed with water and dried prior to storage (Fig. 5a,b).

According to Prasad (2016), nanocrystalline iron (III) oxide was synthesized through green reduction of a precursor iron (II) sulphate heptahydrate using leaf extract of garlic vine (Fig. 6a-c). The structural and compositional characterization of iron abundance in the extracts was estimated through Atomic Absorption Spectroscopy, XRD, UV-vis analysis and FT-IR measurements. On the other hand, Wang et al. (2014) reported the biosynthesis of spheroid-shaped iron nanoparticles using dried eucalyptus leaf extracts. Nanoparticles were prepared with deionized water as solvent and characterized using SEM, EDS and XRD for morphology and composition studies and FTIR to provide information on vibrational characteristics of chemical functional groups. In a study involving over two dozen different tree species, leaf extracts were utilized for the synthesis of nanoscale zerovalent irons via a green and cost-effective method. Optimum reaction conditions such as temperature, time and volume:mass ratio were determined during the synthesis process. Optimum reaction time for most species of tree leaf extracts was $20 \mathrm{~min}$ at $80{ }^{\circ} \mathrm{C}$, the highest temperature studied. The presence of synthesized nanoparticles was indicated by a dark colouration after reacting plant extract with iron (III) solution, with oak, pomegranates and green tea leaves producing the best result (Machado et al., 2013a,b).

Wei et al. (2016b) have reported the synthesis of iron nanoparticles using citrus maxima peels. This method has proven effective for waste minimization and efficient resource utilization as citrus maxima peels, which would otherwise be discarded as the waste/by-product resulting from production of juice is utilized. Peels were extracted using ultrapure water at high temperature for $80 \mathrm{~min}$, centrifuged and filtered through a membrane. Subsequently, extracts obtained were added to Iron (III) chloride solution at room temperature to obtain iron nanoparticles. The synthesis of zerovalent iron nanoparticles from three plant extracts (Rosa damascene (RD), Thymus vulgaris (TV), and Urtica dioica (UD)) have been carried out by Fazlzadeh et al. (2017). Dried leaves of the three plants were extracted at $80{ }^{\circ} \mathrm{C}$ with deionized water as the solvent, filtered, and reacted with iron (II) tetrahydrate solution at a ratio of 2:3. Formation of iron nanoparticles was evidenced by the black coloured precipitates formed. Nanoparticles obtained were irregular in shape with a diameter of $100 \mathrm{~nm}$. In addition, the synthesis of iron hexacynanoferrate nanoparticles with size range 10-60 nm using dried sapindus-mukorossi plant as natural surfactant and water as solvent has been documented (Shanker et al., 2017). In this study, 


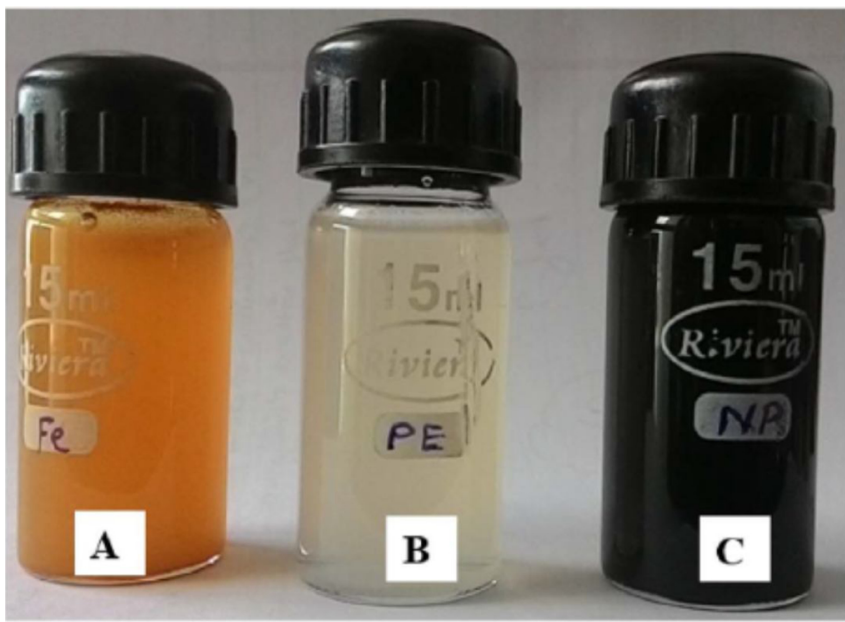

a

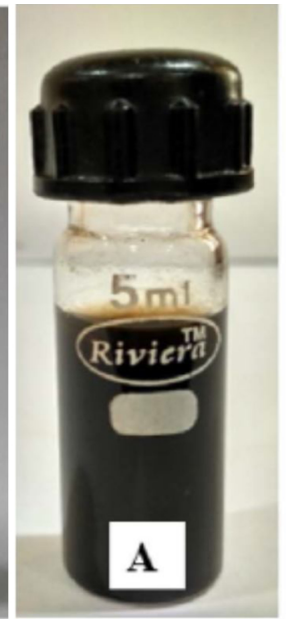

A

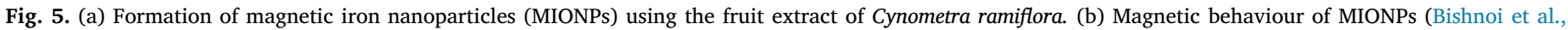
2017).

pulverized plant material was dissolved in double distilled water and the extract obtained was reacted with potassium ferrocyanide for $2 \mathrm{~h}$. The nanoparticles obtained were further characterized using TEM and SEM.

The photo-catalyzed synthesis of magnetic iron oxide nanoparticles using silky hairs of corn and outer leaves of Chinese cabbage was reported (Patra and Baek, 2017). Both plant materials were chopped and extracted with distilled water prior to filtration. The extracts were subsequently applied for synthesis of nanoparticles with iron (II) chloride and iron (III) chloride as precursor compounds under photocatalytic conditions. The extracts served as reducing agents in the reaction while sodium hydroxide was added to facilitate uniform precipitation of nanoparticles, evidenced by black colouration. Prasad et al. (2017a,b,c,d) synthesized well-dispersed magnetic iron oxide nanoparticles with uniform size of 45-60 nm using pomegranate leaves. Dried and ground pomegranate leaves were refluxed with distilled water, filtered and extracts stored at $4{ }^{\circ} \mathrm{C}$. The prepared extracts were then reacted with iron (III) chloride solution as a precursor in a ratio of 1:2. Appearance of black colouration indicated the formation of nanoparticles.

Tangerine peel extract has been utilized for the synthesis of iron oxide magnetic nanoparticles and reported (Ehrampoush et al., 2015). Tangerine peel was collected, dried, milled, boiled with distilled water and the resulting solution filtered to obtain extracts. Plant extract was then reacted with iron (II) solution and iron (III) solution to obtain uniform, spherical-shaped nanoparticles with size ranging from $50-200 \mathrm{~nm} .25 \%$ hydroxylamine was added to the mixture to facilitate uniform precipitation. Nanoparticles were formed as brown precipitates.
Reduced graphene oxide/iron oxide nanocomposite has been synthesized from the leaves of Murrayakoenigii as reported by Prasad et al. (2017a,b,c,d). This was achieved by extracting plant leaves using hot distilled water as solvent, preparing reduced grapheme oxide under reflux by mixing plant extract with a colloidal suspension of grapheme oxide for phytochemical reduction, synthesizing iron oxide magnetic nanoparticles with iron (III) chloride solution as precursor and Murrayakoenigii leaves extract as reducing agent and finally, preparing grapheme oxide/iron oxide nanocomposite by mixing plant extract with graphene oxide and iron (III) hexahydrate solution. Iron oxide nanoparticles of approximately $12 \mathrm{~nm}$ size were prepared and the nanocomposite showed spherical shape. Characterization was carried out using spectroscopic and microscopic techniques. Prasad et al. (2017a,b,c,d) have reported the synthesis of iron oxide nanoparticles using peels of pisum sativum - the plant extract acting as reducing agent. Prior to synthesis of iron oxide nanoparticles, plant peels were extracted with distilled water and filtered. Iron (III) chloride was utilized as the precursor and mixed with pisum sativum peels extract at $80^{\circ} \mathrm{C}$. Spherical nanoparticles with average size of $20-30 \mathrm{~nm}$ were synthesized and characterized. Moringa oleifera leaves were utilized in the synthesis of nickel supported iron oxide magnetic nanoparticles. Powdered plant leaves were refluxed with deionized water and filtered for synthesis of nanoparticles. Extract obtained was mixed with iron (III) chloride and nickel chloride solutions at $\mathrm{pH} 10$. The resultant mixture was centrifuged and nanoparticles formed collected for degradation studies on organic dye. Spherical shaped ferromagnetic nanoparticles were obtained.

Zerovalent ion nanoparticles with a size range of $2-10 \mathrm{~nm}$ have been synthesized from yeast extracts (Mehrotra et al., 2017). Yeast
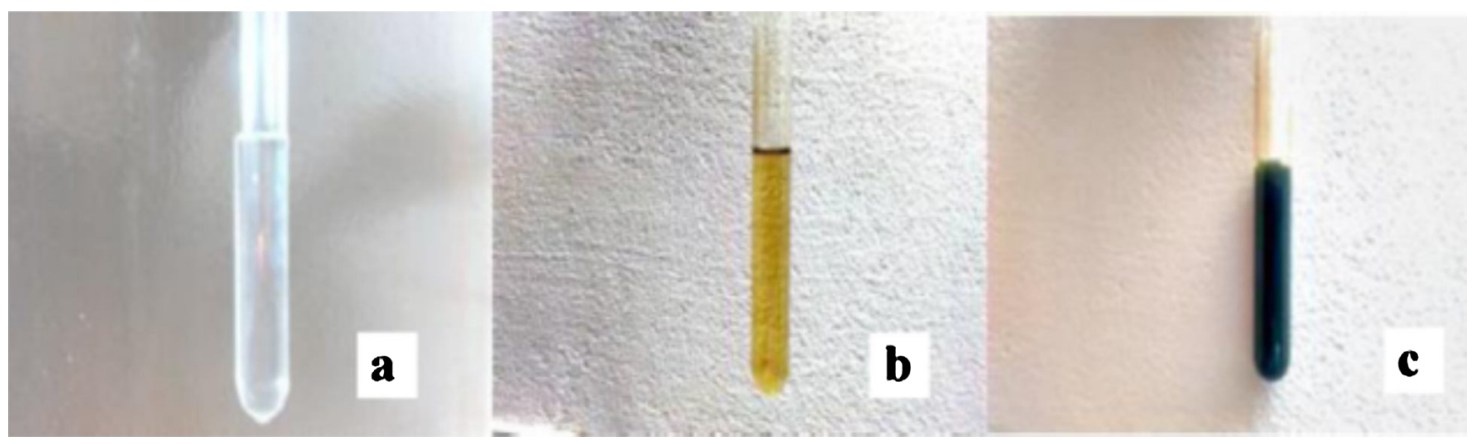

Fig. 6. (a) Precursor - $\mathrm{FeSO}_{4} \cdot 7 \mathrm{H}_{2} \mathrm{O}$, (b) Leaf extracts of Garlic Vine, and (c) Formation of Fe-NP-GV nanoparticles (Prasad, 2016). 
solution, prepared by boiling yeast powder in distilled water, was used as the reducing agent and iron (III) chloride solution as the precursor in the preparation of the nanoparticles. On centrifugation, the nanoparticles formed were characterized using surface plasma resonance, $\mathrm{X}$ ray diffraction and transmission electron microscopy. Tetragonal crystalline-shaped iron oxide nanoparticles with average size of about 29 $\mathrm{nm}$ has been synthesized from the leaves of Sageretia thea (Khalil et al., 2017). Pulverized plant leaves were extracted with deionized water to obtain bioactive components, which in turn acted as reducing agent when reacted with a precursor. Iron sulphate pentahydrate salt acted as the precursor for the synthesis of these nanoparticles when reacted with plant extract. As in most processes reported in literature, the formation of iron oxide nanoparticles is marked by a colour change, mostly from lighter to deeper colour such as yellow to black or brown to violet (Ehrampoush et al., 2015; Patra and Baek, 2017; Prasad et al., 2017a,b,c,d).

Borja et al. (2015) have reported the synthesis of nanoscale zerovalent iron using polyphenols obtained from dried green tea extract. Polyphenols, which are abundant bioactive compounds especially in leaves of several plants, were microwave-extracted from green tea leaves to obtain nanoparticles with particle size ranging from 8 to 23 $\mathrm{nm}$. Powdered green tea leaves were extracted with ethanol, allowed to cool, and then filtered. Plant extract containing polyphenols was reacted with iron (III) chloride solution to synthesize zerovalent iron nanoparticles. Optimum conditions for maximum nanoparticles yield depended on three factors: plant material:solvent ratio, precursor:plant extract ratio and delivery rate of plant extract into precursor solution. Spherical-shaped amorphous zerovalent iron nanoparticles with average particle size of 20-80 $\mathrm{nm}$ have been synthesized using leaves of Eichhornia crassipes (a water hyacinth) (Wei et al., 2017). In order to determine optimum conditions for extraction of bioactive components from the plants using distilled water as extracting solvent, studies on extraction optimization were carried out. Parameters considered include ratio of plant material weight:volume of solvent, $\mathrm{pH}$ and temperature. Optimum volume ratio of precursor solution:plant extract was achieved at 1:1 while plant leaf weight:solvent volume ratio was set at 6 $\mathrm{g} / 100 \mathrm{~mL}$. Similarly, the synthesis of spherical iron nanoparticles with average particle size of $20-60 \mathrm{~nm}$ from Eichhornia crassipes leaves (and two other weeds namely Lantana camara and Mimosa pudica) using ferric chloride $\left(\mathrm{FeCl}_{3}\right)$ precursor has been reported (Prabhakar et al., 2017). Morphology of L. Camara and M. pudica synthesized nanoparticles showed irregular and aggregated quasi-spherical nanoparticles respectively, with larger particles size distribution in comparison to $\mathrm{E}$. crassipses (Table 3).

Silybum marianum $L$. seeds have been used to synthesize coppersupported iron oxide nanoparticles (Sajadi et al., 2016). Spherical nanoparticles with particle size ranging from $8.5-60 \mathrm{~nm}$ was synthesized. Plant seed extract was prepared by boiling powdered seeds in distilled water, centrifuging extract and then filtering. Thereafter, synthesis of $\mathrm{Cu} / \mathrm{Fe}_{3} \mathrm{O}_{4}$ nanoparticles, was carried out by mixing plant extract with iron (III) chloride and copper (II) chloride solutions as precursors. The $\mathrm{pH}$ of the mixture was adjusted with $\mathrm{Na}_{2} \mathrm{CO}_{3}$ to indicate colour change on formation of nanoparticles. Sathya et al. (2017a) have reported the synthesis of iron oxide nanoparticles from the leaves of Coriandrum sativum using ferric chloride as the precursor. Spherical nanoparticles with size ranging from $20-90 \mathrm{~nm}$ was prepared and characterized using FTIR, SEM with EDX. Two methods were experimented with during the nanoparticle synthesis namely: continuous stirring and ultrasonication. However, it is noteworthy that ultrasonication has the advantage of shorter reaction time.

Iron oxide nanoparticles with uniform shape and particle size ranging from 7-13 nm have been synthesized from green tea leaves (Singh et al., 2017). To extract bioactive components - mostly polyphenols, from plant material, powdered tea leaves was mixed with aqueous methanol solution, refluxed and decaffeinated first with methylene chloride, then ethyl acetate via a liquid-liquid extraction process. Polyphenols act as reducing agents and antioxidants when reacted with the precursor in the synthesis of the iron oxide nanoparticles, limiting the oxidation of $\mathrm{Fe}^{2+}$ to $\mathrm{Fe}^{3+}$. Mixture of iron (III) chloride hexahydrate and iron (II) sulphate heptahydrate in distilled water serves as the precursor. Dendrite-like Iron oxide/palladium nanocomposites with average particle size of $50 \mathrm{~nm}$ have been synthesized from pepper extract and applied for the photocatalytic degradation of dye (Khaghani and Ghanbari, 2017). $\mathrm{Fe}_{3} \mathrm{O}_{4}$-Pd nanocomposites were prepared by reacting $\mathrm{K}_{2} \mathrm{PdCl}_{4}$ precursor solution with pepper extract at $160{ }^{\circ} \mathrm{C}$. Nanoparticle morphology and particle size determination was carried out using SEM, TEM and FTIR. An important area of study for researchers is to understand the reduction potential of different plant extracts based on the most bioactive components as this will inform the choice of plant and plant part most efficient in preparing nanoparticles and their subsequent application in different fields. Cyclic voltammetry has been applied to study the redox potential of aqueous extract of dried Terminalia chebula fruit, a plant rich in polyphenolic content. A reduction potential of $0.63 \mathrm{~V}$ was obtained and this is sufficient for metal reduction while Camellia sinensis (green tea), another plant which has been reported for synthesis of nanoparticles showed redox potential of $0.33 \mathrm{~V}$ (Mohan Kumar et al., 2013). During the green synthesis of iron nanoparticles and Iron/Nickel bimetallic nanoparticles from the methanol extract of eucalyptus leaf, Weng et al. (2017) carried out GCMS analysis of extracts before and after nanoparticle synthesis to identify the components present. Identification of compounds was based on comparison between the fragmentation pattern obtained in the mass spectra and those of a mass library. Alkanes, phenols, aldehydes and amines were the major constituents, and there was a decrease in the percentage peak areas of the extracts before and after nanoparticle synthesis, indicating that these bioactive components participate in reduction and capping.

Saikia et al. (2017) have reported the synthesis of silica-supported iron oxide nanocomposite synthesized from powdered fruit extract and rice paddy husk. Firstly, iron oxide nanoparticles were synthesized from fruit extract of Zanthoxylum rhetsa, a medicinal plant with iron (III) solution as precursor. Appearance of brown precipitate indicated formation of nanoparticles, which were then filtered, washed and heated. Next, silica was prepared from combusted rice straw, which was boiled with sodium hydroxide solution, cooled, filtered and treated with sulphuric acid. The resultant white precipitate formed was dried at $100{ }^{\circ} \mathrm{C}$ to obtain silica. Finally, prepared iron oxide nanoparticles and silica were refluxed with methanol to obtain nanocomposites which were then filtered, washed and dried until a brown silica supported ironbased nanocomposites were formed. This was then characterized using FTIR, XRD, SEM-EDX, HR-TEM and NMR and applied as a catalyst for the ipso-hydroxylation of boronic acid in water.

Neem leaf extract has been utilized for synthesis of zinc oxide supported-iron oxide nanoparticles with equal volume of $\mathrm{FeSO}_{4}$ and $\mathrm{FeNO}_{3}$ solutions as precursors (Madhubala and Kalaivani, 2017) (Fig. 7). First, brick-like iron oxide nanoparticles with average particle size of $38 \mathrm{~nm}$ were synthesized from dried and pulverized leaf extract. Subsequently, zinc oxide was mixed with as-synthesized $\mathrm{Fe}_{3} \mathrm{O}_{4}$ nanoparticles, ultrasonicated, and autoclaved at $200{ }^{\circ} \mathrm{C}$ for $18 \mathrm{~h}$. Samples obtained were washed with deionized water and dried overnight. Characterization was carried out using XRD, FTIR, SEM-EDX, TEM and TGA to obtain ellipsoid-shaped $\mathrm{Fe}_{3} \mathrm{O}_{4} @ \mathrm{ZnO}$ nanoparticles with average particle size ranging from 45 to $61 \mathrm{~nm}$.

Manquián-Cerda et al. (2017) have reported the synthesis of oxide, oxyhydroxides and zerovalent iron particles from blueberries. Non-agglomerated nanoparticles with irregular shape and average particle size of $52 \mathrm{~nm}$ were obtained and characterized with TEM, SEM, BET and XRD. Prior to synthesis of nanoparticles, reducing capacity of aqueous extracts of blueberry leaves and shoot was analysed using ferric reducing antioxidant power (FRAP) assay and total phenolic content was determined using a Folin-Ciocalteu reagent. Absorbance measurement was then carried out with UV/VIS Spectroscopy. 


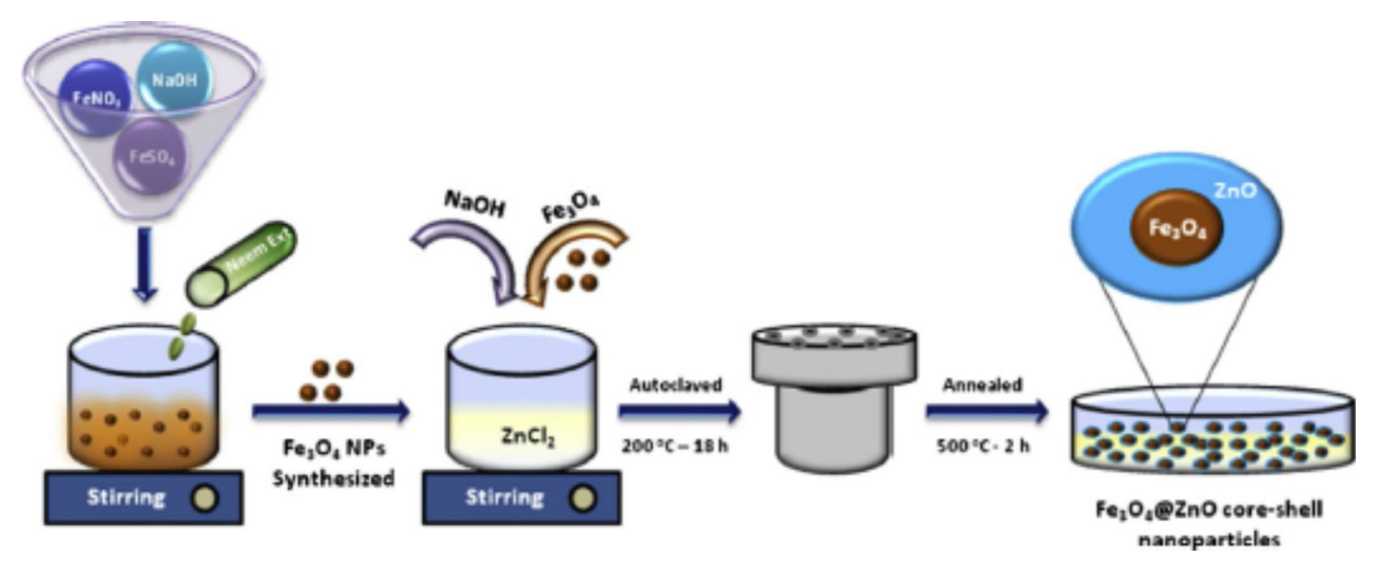

Fig. 7. Schematic diagram of $\mathrm{Fe}_{3} \mathrm{O}_{4} @ \mathrm{ZnO}$ core-shell nanoparticles synthesis (Madhubala \& Kalaivani, 2017).

Green synthesized magnetite, hematite and wuestite nanoparticles immobilized on bariumalginate beads has been synthesized and characterized (Natarajan and Ponnaiah, 2017). Immobilization of iron nanoparticles on the polymeric support (barium alginate beads) was carried out to limit agglomeration. Other polymers utilized include chitosan, agarose, and cellulose. Firstly, iron was extracted from red mud obtained from aluminium industry waste. Next, Syzygium cumini leaf extract was utilized for the synthesis of iron nanoparticles with iron oxalate obtained from red mud serving as precursor. Nanoparticles were collected as black precipitates over ethanol, dried in hot air oven and pulverized to remove agglomerates. This differs from chemical synthesis reported by the same researchers where nanoparticles were obtained by borohydride reduction. Entrapment of nanoparticles was carried out by mixing $S$. cumini based NPs with $2 \% \mathrm{w} / \mathrm{v}$ alginate-water mixture, then injecting this into $2 \% \mathrm{w} / \mathrm{v}$ barium chloride solution dropwise. This is left to harden before being washed and characterized by XRD, FTIR and field emission scanning electron microscopy (FESEM). Green-based ionic liquid iron oxide nanocomposite prepared from black tea extract have been successfully applied for the degradation of propranolol (a contaminant drug residue) (Ali et al., 2017). Firstly, iron oxide nanoparticles were synthesized with $0.1 \mathrm{M}$ ferrous sulphate solution as precursor. Appearance of black colouration indicated formation of nanoparticles, which were separated by centrifugation and washed. Next, nanocomposite was prepared by sol-gel method with $\mathrm{N}$-methyl-butyl-imidazolium-bromide ionic liquid and poly vinyl alcohol surfactant. Finally, nanocomposites were characterized and observed to have amorphous shape with average particle size of 5-50 nm.

\section{Capping and biostabilisation in nanoparticles synthesis}

\subsection{Effects of stabilizing/capping agents}

The use of surfactants as stabilizing/capping agents in nanoparticle synthesis improves dispersion, reduces agglomeration and increases adsorption capacity of nanoparticles. For instance, cetyltrimethylammonium bromide (CTAB), a cationic surfactant has been studied for stabilization and capping of green synthesized iron oxide nanoparticles and its resultant effect on removal of phosphate via an eco-friendly approach (Gan et al., 2018; Cao et al., 2016). In the case of Gan et al. (2018), capped and uncapped nanoparticles were prepared using Eucalyptus leaf extract as reductant with $\mathrm{FeCl}_{3} \cdot 6 \mathrm{H}_{2} \mathrm{O}$ and sodium acetate as precursors. With uncapped nanoparticles, $80 \%$ removal of phosphate with initial concentration of $20 \mathrm{mg} / \mathrm{L}$ was achieved within an hour. However, CTAB-capped nanoparticles - with an optimum surfactant concentration of $0.4 \mathrm{mM}$, showed higher removal efficiency (95\%) within one hour. Cao et al. (2016) studied the effect of temperature, adsorbent dose, initial phosphate concentration and $\mathrm{pH}$ on adsorption of phosphate using CTAB-stabilized irregular, sphericalshaped iron oxide nanoparticles synthesized from Eucalyptus leaves extract. Increase in temperature led to increase in adsorption capacity, which is accounted for by the increase in activation energy, which favours an endothermic process. As dosage of CTAB-based adsorbent increases, the adsorption efficiency increases, then decreases due to saturation of the active sites. Increasing the initial concentration of phosphate led to increased absorption until the maximum adsorption capacity was attained at $60 \mathrm{mg} / \mathrm{L}$. Also, adsorption capacity decreased at highly basic $\mathrm{pH}(\mathrm{pH} 11-13)$ due to electrostatic repulsion between phosphate anions and iron oxide active sites but did not increase significantly at lower $\mathrm{pH}$ (1-9). Rather than electrostatic interaction, a major contributor to the adsorption of phosphate over wide ranging $\mathrm{pH}$ values could be accounted for by ligand exchange.

\subsection{Potential mechanism of nanoparticles synthesis}

The actual reaction pathway of biomimetic nanoparticles synthesis has not been clearly elucidated. From previous studies, phenolic compounds, alongside other phytochemicals such as alkaloids, tannins and organic acids have successfully acted as reducing agents when reacted with metal precursors leading to the formation of nanoparticles (Ali et al., 2016, 2019; Khatami et al., 2019; Karpagavinayagam and Vedhi, 2019; Lakshmi et al., 2019; Vasantharaj et al., 2019). It is expected that the biosynthetic fabrication of nanoparticles could be due to contributions from different biomolecules, and not just a single molecule. Hence, the reaction pathway may vary depending on different plants, or different extraction solvents for the same plant. Other factors such as $\mathrm{pH}$ and geographical location where plants were sampled may be important too. Different stages can be proposed such as bioreduction, capping/stabilization, condensation and calcination as indicated in the following schemes:

Scheme 1:

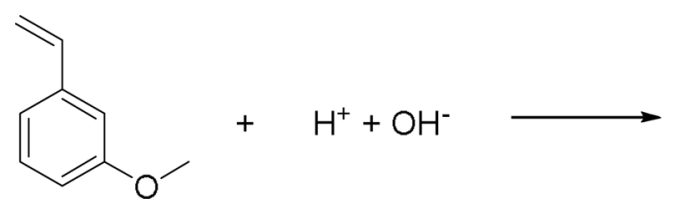


Scheme 2:

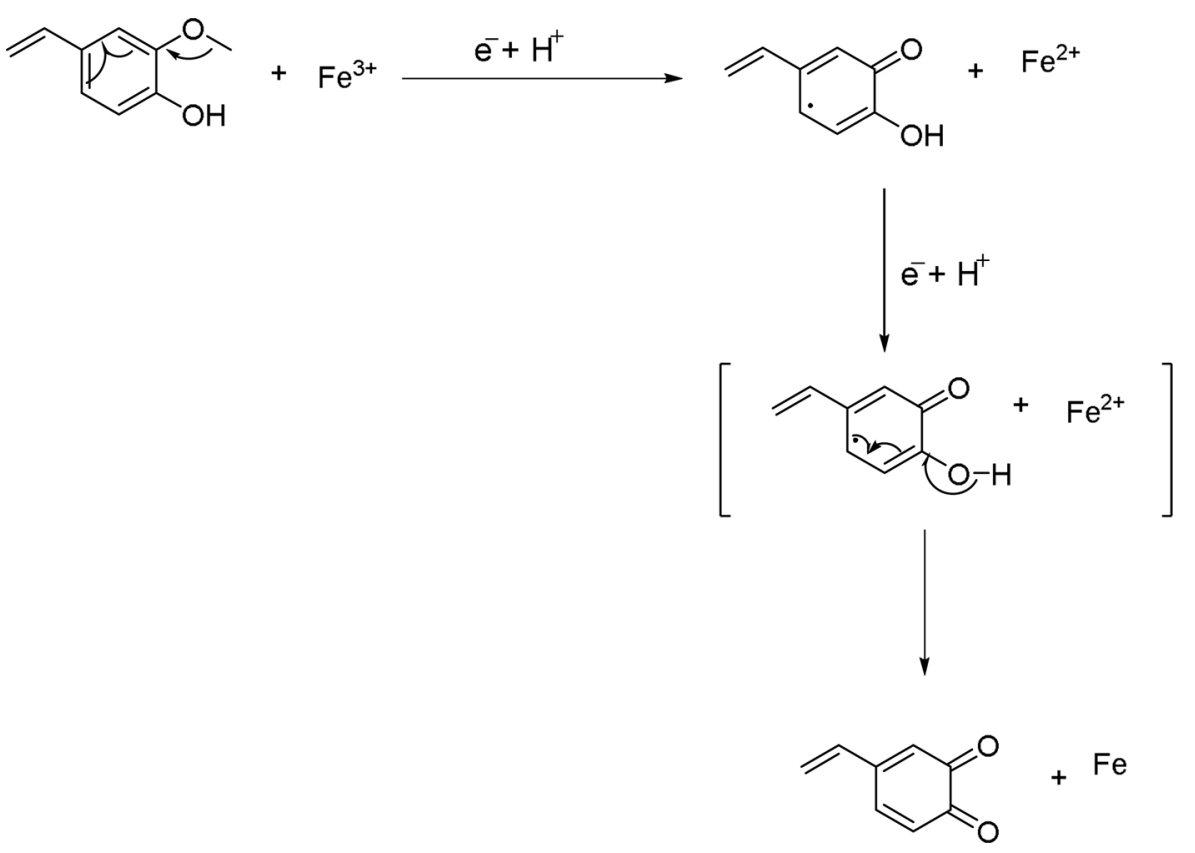

Scheme 3:

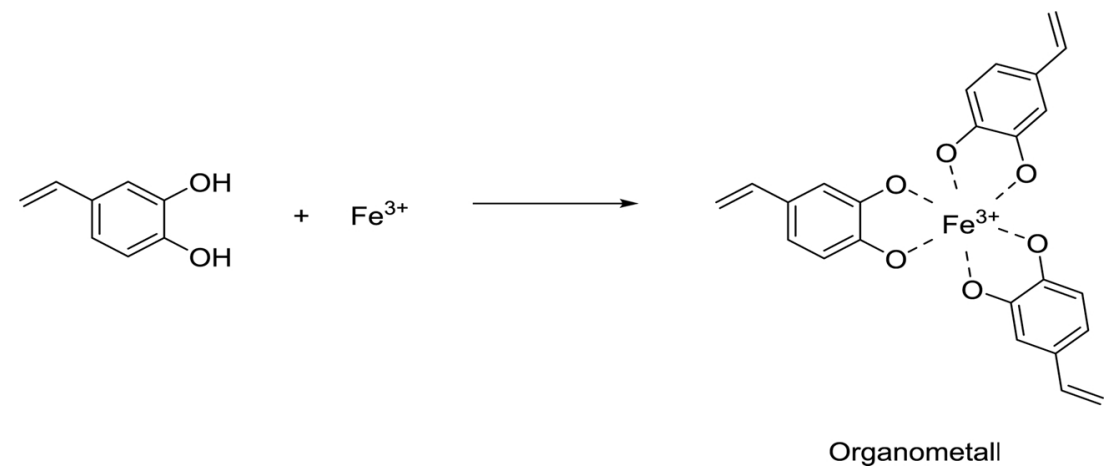

Scheme 4 represents the reaction mechanism for thermal decomposition of source precursor and iron complex at $600{ }^{\circ} \mathrm{C}$ in static air. This process, known as calcination, results in the formation of iron and iron oxide nanoparticles. 
Scheme 4:

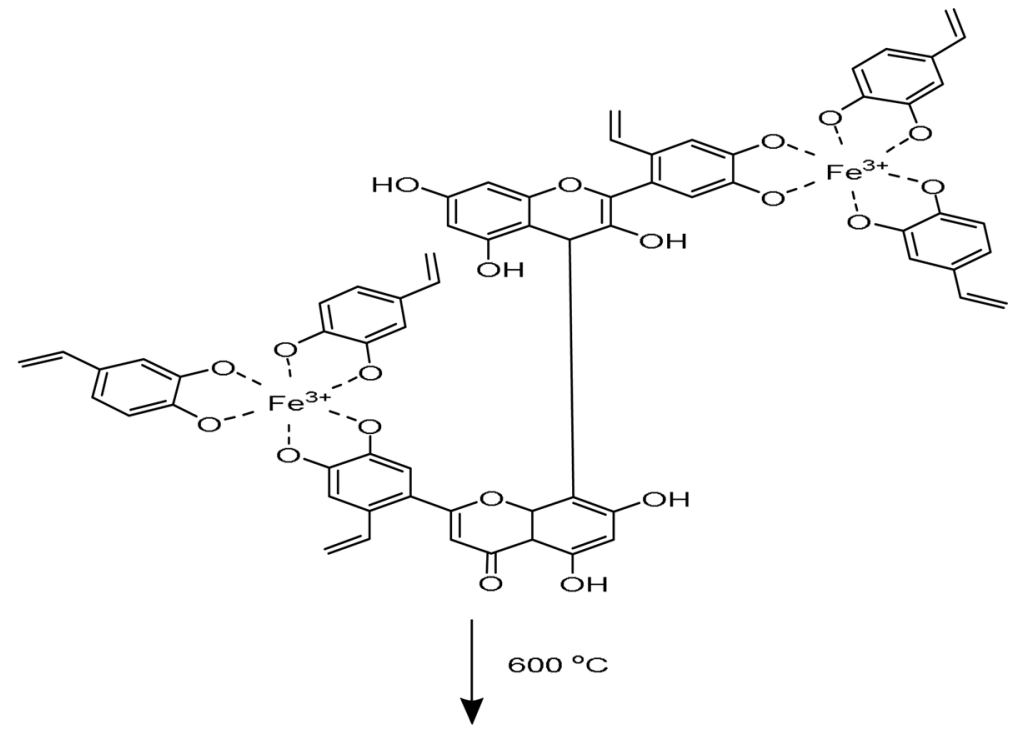

proposed condensation mechanism of Fe-polyphenol

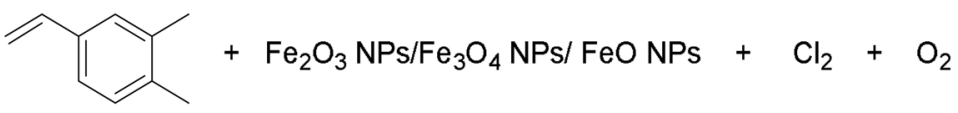

SUMMARY

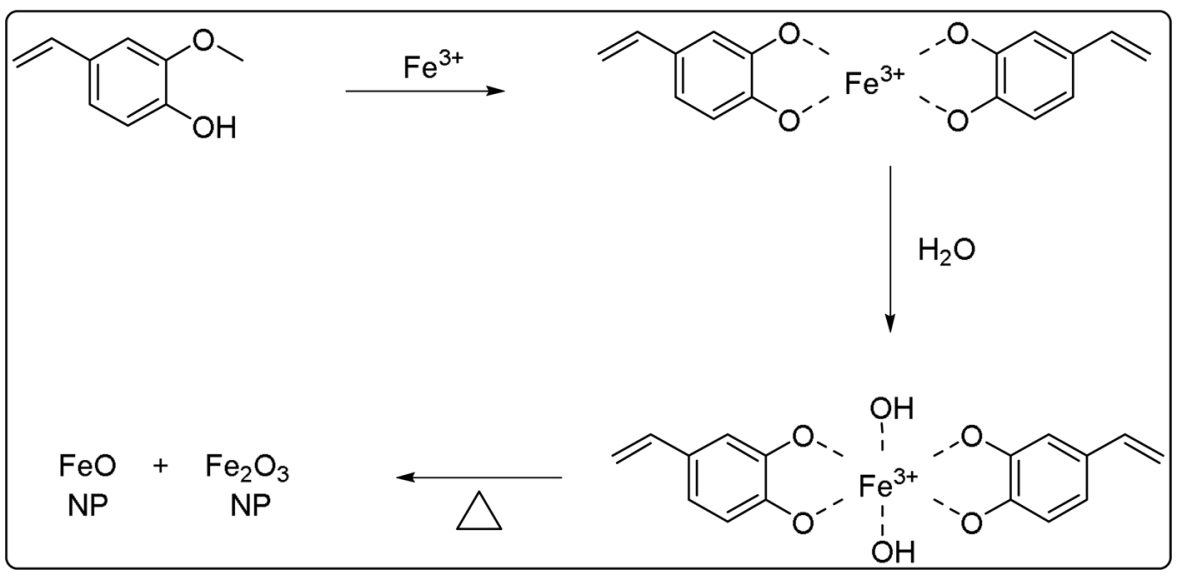

Schemes 1-4 provide an insight into the mechanisms involved in biofabrication of nanoparticles. Bioreduction involves a reduction-oxidation reaction between phytochemicals and metal precursors thereby converting them into their corresponding metal nanoparticles. Several researchers such as Nasrollahzadeh et al. (2017) have attempted to describe the bioreduction mechanism. During this process, green nanoparticles go through activation, growth and termination phases. At the activation phase, iron ions are recovered from their salt precursors, reduced by plant phytochemicals and transferred from their trivalent to di- and zero-valent states $\left(\mathrm{Fe}^{3+} / \mathrm{Fe}^{2+}\right.$ to $\left.\mathrm{Fe}^{0}\right)$. During the growth phase, metal atoms aggregate to form a diverse range of nanoparticles such as nanowires, nanotubes and nanospheres. At the termination phase, nanoparticles are capped by plant phytochemicals, thereby attaining stable morphology.

Schemes 1 and 2 describe the possible bioreduction mechanism for formation of iron/iron oxide nanoparticles using leaf extract of Azadirachta indica. Aqueous extract of $A$. indica contains phenolic compounds such as 2-methoxy-4-vinylphenol (as characterized using GC-MS), which ligates with iron-phenol complex (pH 5-7) thereby converting trivalent iron ions to their di - and zero - valent states. Capping and biostabilisation of plant-mediated nanoparticles occurs via complexation reaction between metal ion and phytochemicals. We propose that iron-polyphenol complex is formed - depicted by scheme 3 , resulting in the stabilization of green nanoparticles, thereby reducing aggregation/agglomeration. This precludes need of toxic chemicals for nanoparticles stabilization, in line with the principles of green chemistry.

The synthesis of iron (Fe) nanoparticles (NPs) through green methods and other biological nanotechnologies primarily involves the use of microorganisms (fungi, bacteria, actinomycetes, and viruses), algae, plant and their extracts, agricultural wastes, enzymes and 


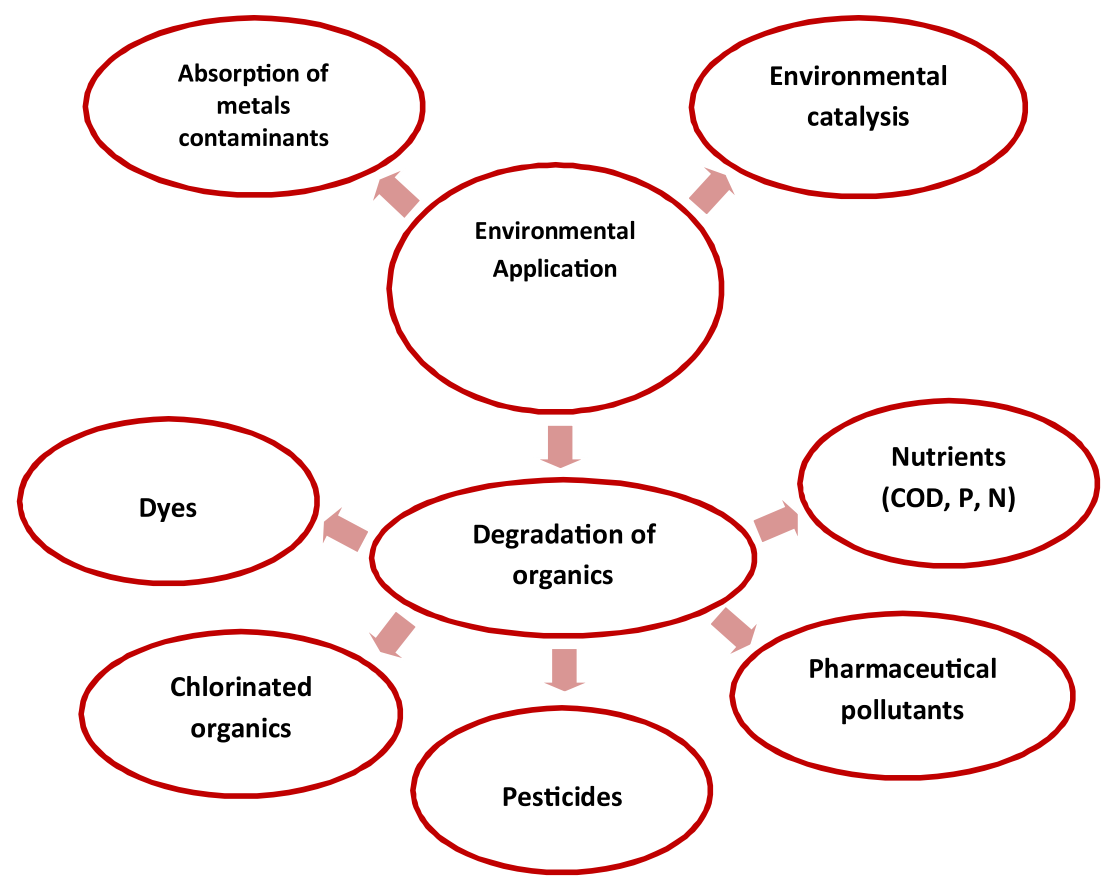

Fig. 8. Illustration of environmental applications of nanomaterials.

biomolecules. Despite the sterling advantages of these green techniques, there are several limiting factors that have been indicated to govern the biosynthesis, characterization, amount, quality and application of the synthesized nanoparticles. These factors include temperature, $\mathrm{pH}$, light, method employed for synthesis of Fe NPs, pressure, time, particle size, concentration of the reactants, pore size, and constituents of the bio-derived extracts (Rai et al., 2006; Darroudi et al., 2011; Kuchibhatla et al., 2012; Tran et al., 2013; Raut et al., 2014; Patra and Baek, 2014; El-Seedi et al., 2019).

\section{Applications of synthesized nanoparticles for environmental remediation}

\subsection{Iron nanoparticles (Fe-NPs) \& magnetic Iron oxide nanoparticles (MIONPs)}

Iron based nanoparticles are smart nanomaterials with magnetic properties, high energy and surface area, which in turn influence reaction rates. The latter property accounts for their susceptibility for agglomeration thereby reducing particle functionality, hence the need for stabilization with various organic and inorganic polymers such as cellulose, chitosan, silica, zeolite and clay, grapheme and metal organic frameworks (MOFs). Nanoparticle stabilization using novel polymeric organic and inorganic materials is being studied. The adsorptive and reductive capabilities of nanoparticles have made them considerable environmental remediation agents, particularly in situ processes. They are cheap, non-toxic and effective for degradation of a wide range of contaminants -organic and inorganic (Fig. 8). Furthermore, they can be synergistically combined with other techniques such as chemical oxidation and bioremediation, including activation of chemical oxidants for increased effectiveness i.e. in situ chemical oxidation (ISCO) (Tables 4 and 5).

Saikia et al. (2017) have described an eco-friendly and relatively cheap method for the ipso-hydroxylation of boronic acids to phenol using silica-supported iron oxide nanocomposite as catalyst instead of hydrogen peroxide (Schemes 1). This green approach evades the use of drastic conditions such as high temperatures and toxic reagents/solvents. From literature, about $4 \mathrm{mg}$ of $\mathrm{Fe}_{2} \mathrm{O}_{3} @ \mathrm{SiO}_{2}$ was utilized as a catalyst to obtain $98 \%$ yield within two hours with water as the solvent and at mild temperature $\left(50^{\circ} \mathrm{C}\right)$. No product was formed when the reaction was carried out under inert conditions or in the absence of the silica-supported catalyst.

The complete fenton-like catalytic degradation of Rhodamine B, a carcinogen, using green synthesized iron oxide nanoparticles in the presence of hydrogen peroxide has been reported (Groiss et al., 2017). Optimum reaction conditions were achieved with $1.11 \mathrm{mM}$ nanoparticles synthesized from Cynometra ramiflora leaf extract and $2 \%$ $\mathrm{H}_{2} \mathrm{O}_{2}$ within $15 \mathrm{~min}$. This process is beneficial for wastewater treatment and produces minimal sludge, which is a major disadvantage of traditional fenton-catalyzed mechanisms. Synthesis of reduced graphene oxide/iron oxide based palladium nanoparticles ( $\mathrm{Pd} / \mathrm{RGO} / \mathrm{Fe}_{3} \mathrm{O}_{4}$ ) from the leaves of Withania coagulans - a bushy shrub used a 'magic healer' and commonly found in south east Asia has been reported (Atarod et al., 2016). Reduced graphene oxide, prepared biologically by mixing sonicated suspension of graphene oxide with aqueous extract of Withania coagulans leaves was reacted with ferric chloride solution. The resultant mixture was stirred, refluxed and magnetically separated to obtain $\mathrm{RGO} / \mathrm{Fe}_{3} \mathrm{O}_{4}$ magnetic nanocomposite. Finally, palladium chloride was gradually introduced into the as-prepared nanocomposite to obtain $\mathrm{Pd} / \mathrm{RGO} / \mathrm{Fe}_{3} \mathrm{O}_{4}$ with average particle size of 7-13 nm. The two-stage process for the synthesis of $\mathrm{Pd} / \mathrm{RGO} / \mathrm{Fe}_{3} \mathrm{O}_{4}$ (which was subsequently applied as a recoverable and reusable catalyst) involved the reduction of $\mathrm{Fe}^{3+}$ and $\mathrm{Pd}^{2+}$ using the aqueous extract of Withania coagulans leaves without further surfactants or coagulants. The synthesized nanocomposite was applied for the catalytic reduction of 4nitrophenol to 4-aminophenol in the presence of sodium borohydride and monitored with UV/VIS spectrophotometer. In the absence of the nanocatalyst, 4-nitrophenol was gradually reduced as indicated by the fading of the yellow colour to form 4-aminophenol within a minute. In the absence of the nanocatalyst, there was no reduction and no appreciable colour change was observed. Also, $\mathrm{Pd} / \mathrm{RGO} / \mathrm{Fe}_{3} \mathrm{O}_{4}$ nanocomposite reduced 4-nitrophenol faster than $\mathrm{RGO} / \mathrm{Fe}_{3} \mathrm{O}_{4}$ nanocomposite, which is a pointer to the enhancing effect of palladium nanoparticles on the former.

Xiao et al. (2017) have reported the removal of hexavalent chromium from aqueous solution using zerovalent iron nanoparticles synthesized from Syzygium jambos (L.) Alston leaf extract. Complete removal of chromium is dependent on effect of nanoparticles dosage, 


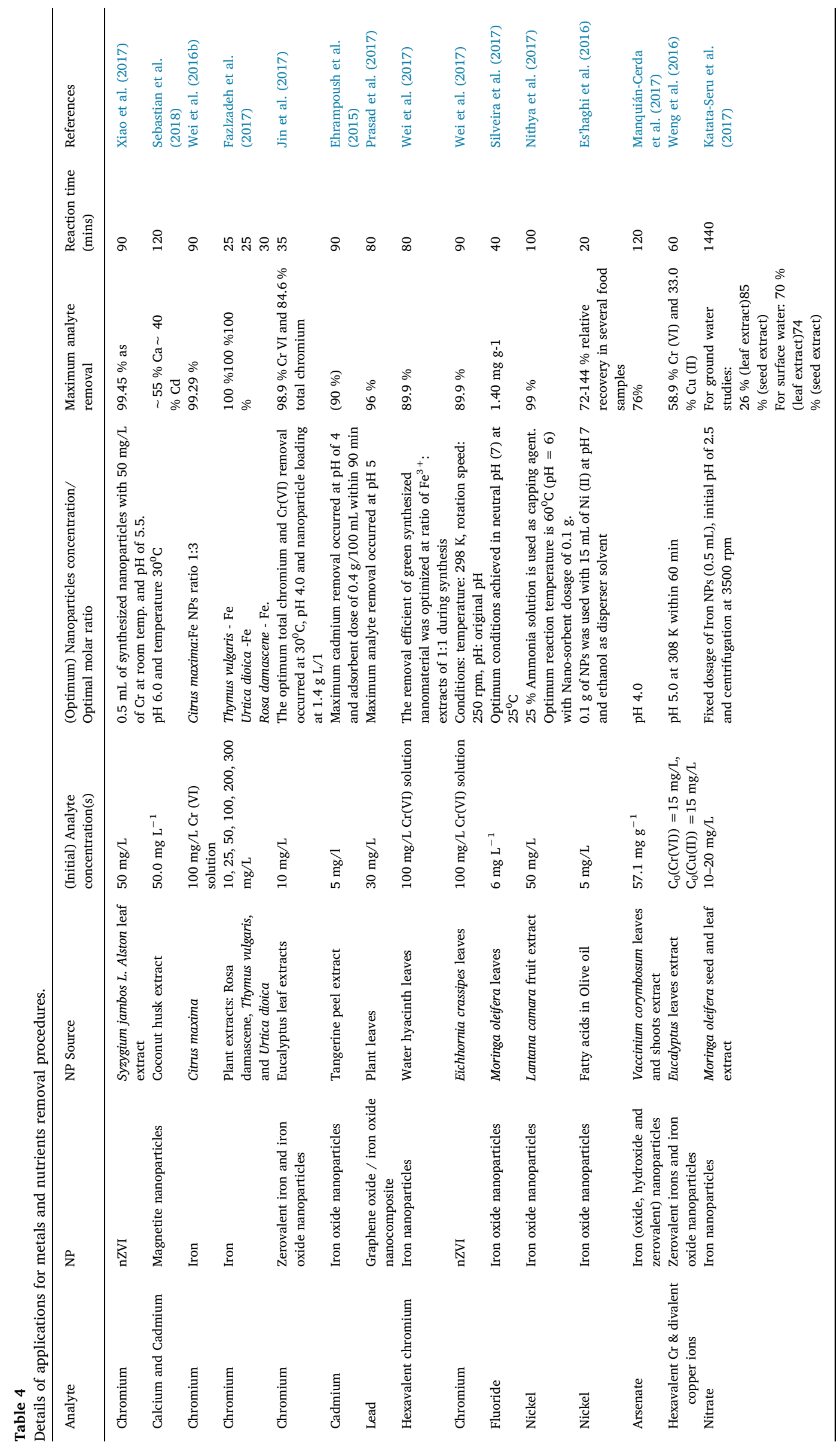




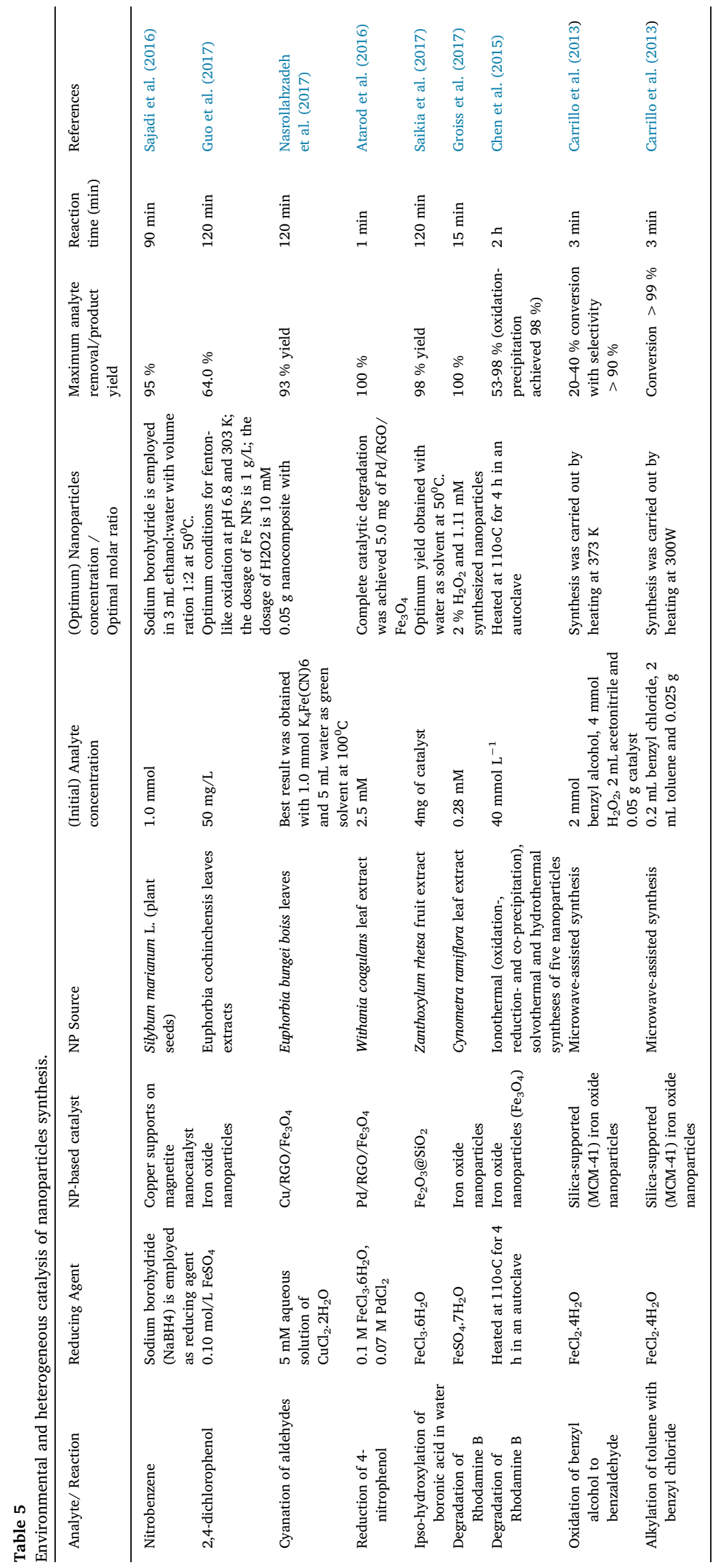



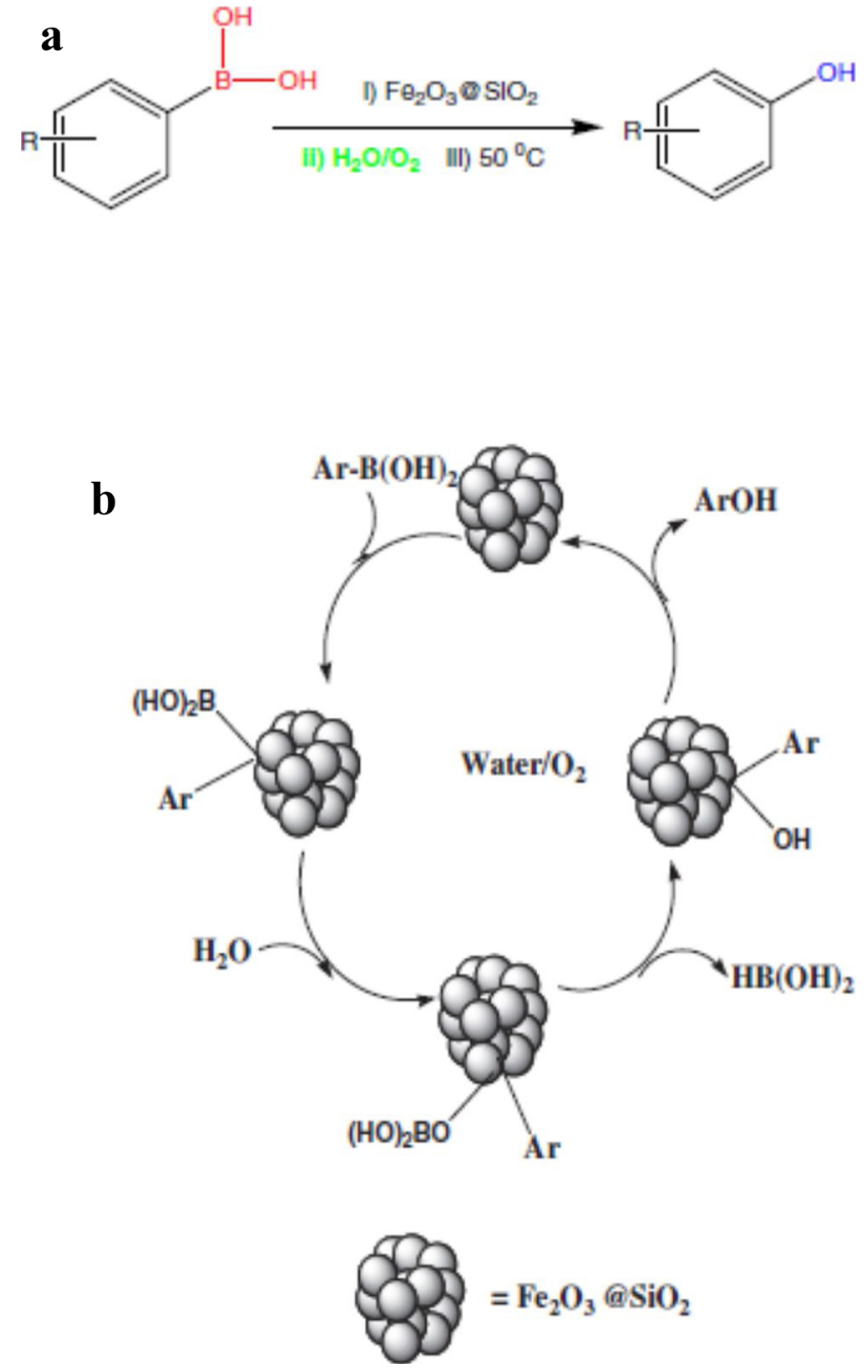

Scheme 1. (a) Ipso-hydroxylation of boronic acid in water. (b) Proposed mechanism in ipso-hydroxylation of phenylboronic acid (Saikia et al., 2017).

temperature, $\mathrm{pH}$ of solution and initial concentration of chromium. As dosage of nanoparticles is increased and concentration of chromium remains unchanged, removal rate of metal ion increases due to increasing availability of active sites. However, removal efficiency decreases as initial concentration of chromium is increased. Increasing temperature from $20^{\circ} \mathrm{C}$ to $60^{\circ} \mathrm{C}$ increased removal efficiency by $15 \%$. Chromium removal is also favoured at acidic $\mathrm{pH}$ due to electrostatic attraction between the protonated nanoparticles surface and charge on hexavalent chromium. An optimum condition for complete removal of chromium was obtained with $0.5 \mathrm{~mL}$ of synthesized nanoparticles with $50 \mathrm{mg} / \mathrm{L}$ of chromium at room temperature and $\mathrm{pH}$ of 5.5. Similarly, the adsorption of low levels of calcium and cadmium using coconut husk extract-synthesized magnetite nanoparticles has been reported (Sebastian et al., 2018). According to this study, more than $40 \%$ of cadmium and about $55 \%$ of calcium were removed within $120 \mathrm{~min}$ with most of the adsorption taking place within the first $30 \mathrm{~min}$ before achieving equilibrium. Initially, the concentration of metal ions was fixed at $50 \mathrm{mg} / \mathrm{L}$ and effect of nanoparticle dosage on adsorption process studied. Increasing adsorbent dosage led to increase in active sites/ surface area and thus the amount of metal ions adsorbed increased until saturation was attained. Also, as $\mathrm{pH}$ was increased from 2 to 6 , there was increased adsorption of the metal ions. At highly acidic $\mathrm{pH}$, the active sites were highly protonated, leading to electrostatic repulsion between positive metal ions and the binding site. Also, metal adsorption was favoured at low and ambient temperatures compared to higher temperatures such as $50^{\circ} \mathrm{C}$. This is because high temperature distorts the electrostatic balance between metal ions and binding sites as there is increased kinetic energy.

The efficiency of iron nanoparticles synthesized from eucalyptus leaves for in situ removal of total nitrogen, phosphorus and COD from poultry breeding wastewater achieved $71.7 \%, 30.4 \%$ and $84.5 \%$, respectively (Wang et al., 2014). Wei et al. (2016b) applied iron nanoparticles synthesized from citrus maxima peels for the removal of $\mathrm{Cr}$ (VI). Complete removal of $\mathrm{Cr}$ (VI) was achieved with Iron (III) solution:citrus maxima extract ration of $1: 3$ within $90 \mathrm{~min}$. More so, Fazlzadeh et al. (2017) has reported on the application of iron nanoparticles synthesized from three plant extracts for the removal of hexavalent chromium from aqueous solutions with efficiency greater than $90 \%$ within 10 min. Application of green synthesized iron hexacyanoferrate nanoparticles for degradation of eight selected priority PAHs in soil and water is available in literature (Shanker et al., 2017). Initial concentration of these high molecular weight PAHs ranged from $50-250 \mathrm{mg} \mathrm{L}^{-1}$. Almost all the PAHs were degraded at optimum $\mathrm{pH}$ of 7.0 to give non-toxic by-products with $80-90 \%$ degradation of anthracene and phenanthrene within $48 \mathrm{~h}$. The degradation pattern in soil was similar to water (Table 6).

Adsorption studies on Congo red (a dye) using green synthesized iron oxide magnetic nanoparticles from pomegranate leaves has been reported (Prasad et al., 2017a,b,c,d). A mixture of the dye suspension, synthesized nanoparticle and $\mathrm{NaBH}_{4}$ were centrifuged and analysed, achieving $93 \%$ dye degradation within one hour. Iron oxide nanoparticles synthesized from tangerine peel extract was applied for adsorption of cadmium, which is usually present as a trace metal in water bodies (Ehrampoush et al., 2015). Maximum cadmium removal occurred at pH 4 within 90 min. $90 \%$ cadmium removal was obtained and removal efficiency of the nanoparticle was determined based on the residual cadmium concentration in the solution. Prasad et al. (2017a,b,c,d) have utilized graphene oxide/iron oxide nanocomposite as adsorbents for removal of $\mathrm{Pb}$ (II) from water. Removal efficiency of the nanocomposite peaked at $96 \%$ at pH 5 with rapid removal of lead ions within half the reaction time of $80 \mathrm{~min}$. Efficiency of the nanoadsorbents is reported to be $\mathrm{pH}$ dependent. Further studies showed that the adsorbents are reusable on treatment with acid to desorb Lead $(\mathrm{Pb})$ ions. More so, studies on degradation of methyl orange dye using iron oxide nanoparticles synthesized from pisum sativum peels have been reported (Prasad et al., 2017a,b,c,d). $96 \%$ of the dye was successfully removed within one hour at optimum $\mathrm{pH}$ of 6 and adsorbent concentration of $0.3 \mathrm{~g} / \mathrm{L}$. Malachite green, an organic dye has been degraded using nickel supported iron oxides nanoparticles synthesized from Moringa oleifera leaves (Prasad et al., 2017a,b,c,d). UV -VIS spectrometer analysis of the dye-nanoparticles mixture shows that over $90 \%$ of the organic dye was degraded within $25 \mathrm{~min}$. Complete degradation of Dichlorvos, an organophosphorus insecticide, has been achieved using protein capped zerovalent ions synthesized from yeast extract (Mehrotra et al., 2017). Maximum degradation was observed when $2000 \mathrm{mg} / \mathrm{L}$ iron nanoparticles were used in the presence of 1000 $\mu \mathrm{l} \mathrm{H}_{2} \mathrm{O}_{2}$ within 60 min.

Wei et al. (2017) reported the removal of hexavalent chromium from solution iron nanoparticles synthesized from the leaves of a water hyacinth. $90 \%$ of $\mathrm{Cr}$ (VI) ions was removed from an initial concentration or $100 \mathrm{mg} / \mathrm{L}$ within $80 \mathrm{~min}$. The removal efficient of green synthesized nanomaterial was optimized at ratio of $\mathrm{Fe}^{3+}$ : plant extracts of 1:1. Sajadi et al. (2016) reported the reduction of nitroarenes using copper-supported on magnetite nanocatalyst. Sodium borohydride was employed as reducing agent for the degradation process. Alone, $\mathrm{NaBH}_{4}$ did not degrade nitrobenzene, but with the introduction of the nanocatalyst, $90 \%$ degradation was achieved within 90 min. Removal of methylene blue (an organic dye pollutant) from solution using iron oxide nanoparticles synthesized from green tea polyphenols has achieved 95 \% removal efficiency within 16 min (Singh et al., 2017). 


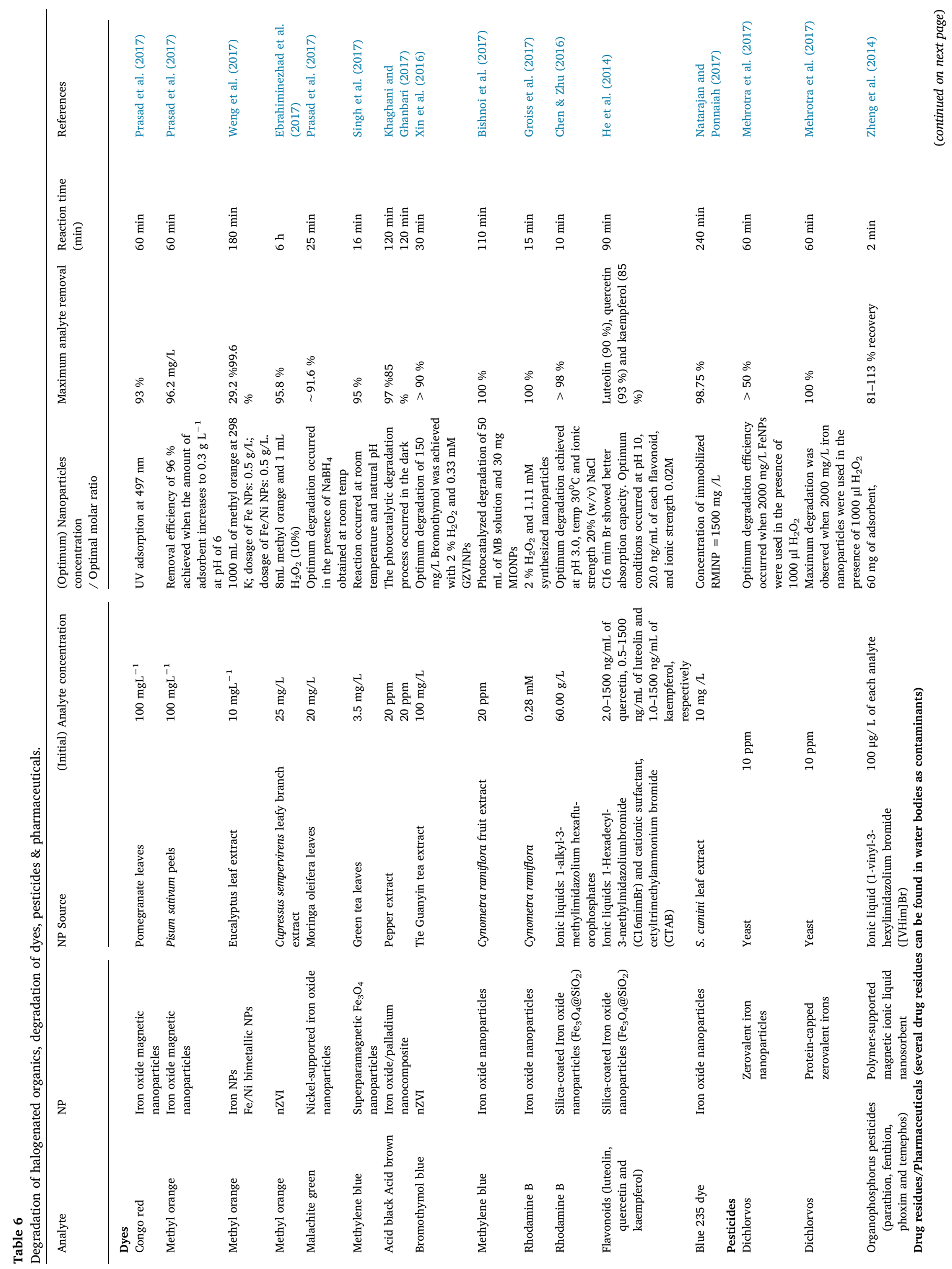




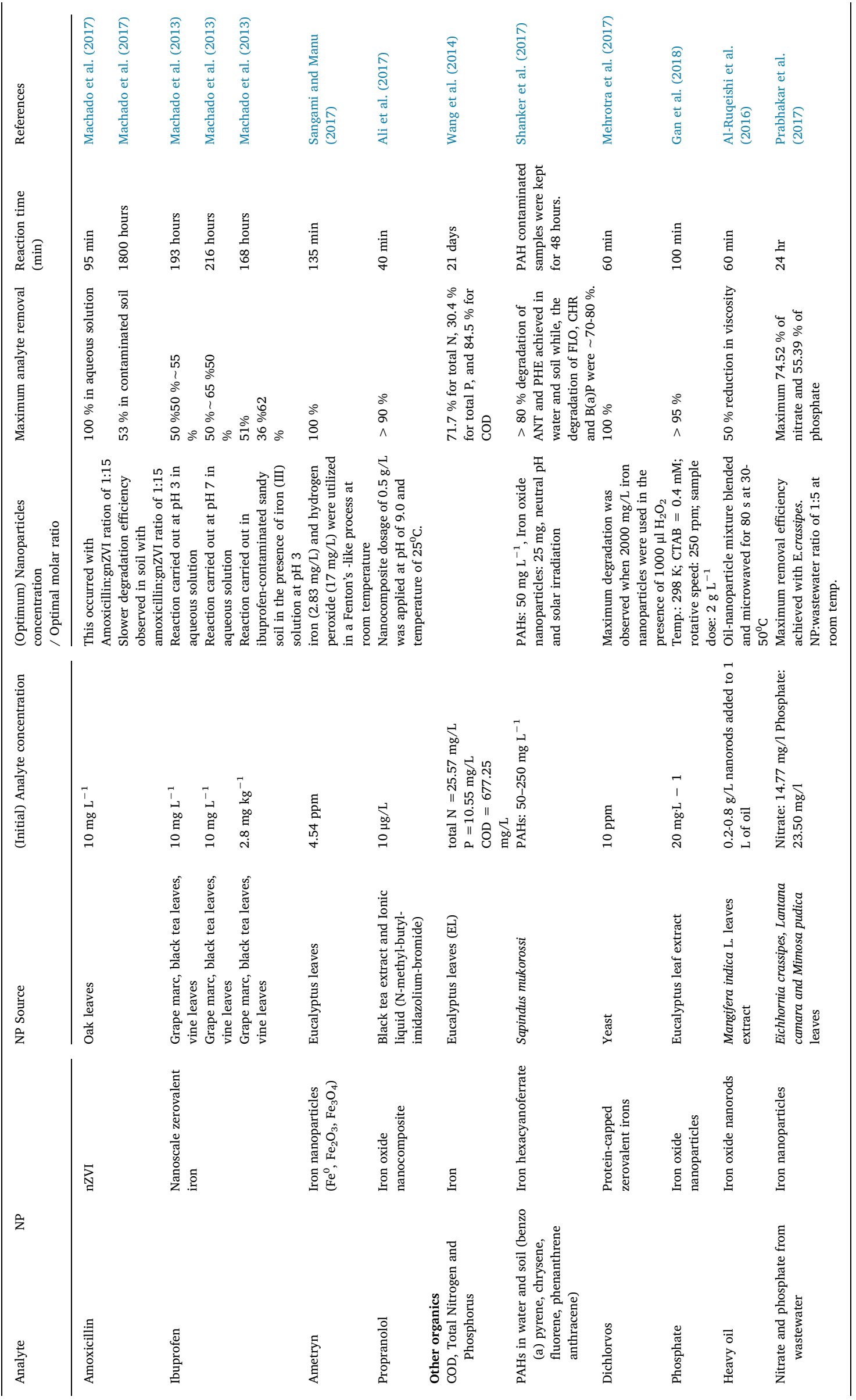


Change in dye concentration on reacting with nanoparticles is determined by measuring residual methylene blue in solution with UV/ VIS spectrophotometer. Degradation of amoxicillin, a common antibiotic has been studied in water and soil using nanoscale zerovalent irons synthesized from oak leaves (Machado et al., 2017). $100 \%$ and 53 $\%$ degradation of the antibiotic was achieved in water and soil respectively after liquid chromatography analysis. Although complete degradation of amoxicillin occurred within $95 \mathrm{~min}$ in aqueous solution at optimum analyte:nanoparticle ratio of $1: 15$, it took $1800 \mathrm{~h}$ to achieve $53 \%$ degradation in soil under similar conditions. This could be due to nanoparticle-soil matrix interaction.

Nithya et al. (2017) have reported the removal of nickel from aqueous solution with iron oxide nanoparticles synthesized from Lantana camara fruit extract using atomic absorption spectrophotometer. Studies were carried out to establish the effect of $\mathrm{pH}$, varying nickel concentration, adsorbent dosage, particle size, contact time and temperature on nickel removal. As acidity decreases from $\mathrm{pH} 1-6$, removal efficiency increases, although at basic $\mathrm{pH}$ nickel will likely form metal hydroxides. Hence, optimum $\mathrm{pH}$ observed is 6 . At lower $\mathrm{pH}$, there is high desorption capacity, which is accounted for by the repulsion between $\mathrm{H}^{+}$rich adsorbent sites and positively charged nickel cations. On the other hand, at higher $\mathrm{pH}$, higher adsorption capacity is obtainable due to attraction between negatively charged groups such as hydroxyl and carboxyl and positively charged cationic nickel ions. Thus, higher $\mathrm{pH}$ facilitates favourable adsorption. Increasing concentration of nickel ions increases sorption capacity but decreases adsorption efficiency due to saturation of the adsorption sites. It was observed that the smaller the adsorbent particle size, the greater the surface area with corresponding increases in adsorption efficiency. At the beginning of the adsorption studies, metal ions were sorbed rapidly but this slowed down as the reaction progressed and can be attributed to initial availability of larger nanoparticle surface area and negatively charged adsorbent sites. Natarajan and Ponnaiah (2017) reported about 99 \% removal of Blue 235 dye using iron oxide nanoparticles synthesized from Syzygium $\mathrm{cu}$ mini leaf extract within $4 \mathrm{~h}$. Al-Ruqeishi et al. (2016) reported the nanorod-based treatment for heavy oil viscosity. Iron oxide nanorods were synthesized from mango tree leaves, blended with heavy crude oil and microwaved for $80 \mathrm{~s}$. Appreciable reduction in viscosity of heavy oil (up to $50 \%$ with $0.6 \mathrm{~g} / \mathrm{L}$ nanorods) is achieved on addition of green synthesized nanorods at $30-50^{\circ} \mathrm{C}$. Microwave assisted extraction of metals $\left(\mathrm{Pb}^{2+}, \mathrm{Cu}^{2+}, \mathrm{Cd}^{2+}\right.$ and $\left.\mathrm{Hg}^{2+}\right)$ from solution using magnetic iron oxide nanoparticles coated with nanosilica layer has been reported (Mahmoud et al., 2016a). Solution containing the metal ion was brought in contact with the nanosorbent and microwaved at $1400 \mathrm{~W}$ within $30 \mathrm{~s}$ with temperature ranging from $26-65^{\circ} \mathrm{C}$. Efficient metal sorption was achieved within $5 \mathrm{~s}$.

Mahmoud et al. (2016b) described a modified co-precipitation method for the synthesis of magnetic iron oxide nanoparticles coated with amino-containing silica support. The synthesized nanosorbent was applied for the sorption of some heavy metals $\left(\mathrm{Pb}^{2+}, \mathrm{Cu}^{2+}, \mathrm{Cd}^{2+}\right.$ and $\mathrm{Hg}^{2+}$ ) from aqueous solution using microwave heating. The dissolved metal ion, in contact with nanosorbent is microwave-heated for a short time and sorbed to nanosorbent surface. $\mathrm{Pb}^{2+}$ showed better sorption capacity than the other metals within $15 \mathrm{~s}$. It was also observed that sorbed metals were not desorbed with increase in temperature. Silicasupported magnetic iron oxide nanoparticles coated with ionic liquids have been applied for the simultaneous extraction and catalytic degradation of contaminants such as organic dyes, proteins, flavonoids and organophosphorus pesticides (Chen and Zhu, 2016; Chen et al., 2015; He et al., 2014). The solid phase microextraction of three flavonoids (luteolin, quercetin and kaempferol) using room temperature ionic liquid $(\mathrm{C} 16 \mathrm{mimBr})$ and surfactant $(\mathrm{CTAB})$ as coating agents on silica-stabilised MIONPs has also been reported (He et al., 2014). Maximum absorption of all three flavonoids using CTAB-coated $\mathrm{MIONP} / \mathrm{SiO}_{2}$ ranged between 25-72 \% while $\mathrm{C}_{16}$ mimBr-coated $\mathrm{MIONP} / \mathrm{SiO}_{2}$ showed better absorption (85-93\%). Polymer-supported magnetic ionic liquid nanosorbent has been utilized in the extraction of organophosphorus pesticides from solution (Zheng et al., 2014). Dispersion of nanosorbent in six solvents for removal of OPPs was evaluated as well as amount of nanosorbent, reusability and reaction time. Methanol proved to be an effective elution solvent, in comparison to hexane and methylene dichloride. Optimum removal of pesticides was achieved with $60 \mathrm{mg}$ of nanosorbent within $1 \mathrm{~min}$.

Hematite quantum dots and nanorods have been synthesized by microwave and microwave-hydrothemal techniques respectively, applied for degradation of an organic dye and compared with commercial hematite (Ahmed et al., 2014a,b). Microwave-assisted ionic-liquid synthesized quantum dots, with average particle size of $\sim 10 \mathrm{~nm}$ displayed better catalytic efficiency for the removal of methylene orange compared with synthesized nanorods (with average diameter of $60 \mathrm{~nm}$ ) and commercial hematite due to its larger surface area. Gas sensing properties of ionic-liquid synthesized hematite nanospheres have been reported for detection of air pollutants (P. Wang et al., 2017). Nanoparticles were synthesized and calcined at high temperatures to obtain better crystallization. Calcined hematite nanoparticles showed high and improved sensitivity to acetone at $170{ }^{\circ} \mathrm{C}$, likely resulting from the increased pore size on calcination. Iron fluoride nanoparticles $\left(\mathrm{FeF}_{2}-\mathrm{NPs}\right)$ have been synthesized in fluorine-containing ionic liquids using amidinate precursors (Schütte et al., 2017). $\mathrm{FeF}_{2}$-NPs have been widely applied as cathodic materials in lithium ion batteries in most electronic appliances. Non-agglomerated nanoparticles which were stable for more than a month without need for extra stabilizers or surfactants were obtained in ionic liquids. ([BMIm] [BF4])-based synthesis yielded NPs with smaller average sizes compared to the other fluorous ionic liquids.

\section{Fate, transport and toxicology of iron nanoparticles}

Rapid advances in the field of nanotechnology have birthed growing concern in the scientific community on the toxicity of nanoparticles on humans and the environment. Owing to their unique morphological features, particle size, surface energy, agglomeration/self-assembly and synthesis process, nanoparticles interact strongly with enzymes in living organisms and metals in environmental media. However, the potential for toxicity is milder with biosynthesized nanoparticles in comparison with physical and chemical processes. This is because toxic capping and stabilizing agents such as hydrazine are rarely employed. In a recent study conducted by Das et al. (2018), strain LS4- a Desulfovibrio bacterium was reportedly responsible for the in situ synthesis of maghemite nanoparticles $\left(\mathrm{Fe}_{2} \mathrm{O}_{3}\right)$ in saltpan sediments obtained from Goa, India. Maghemite nanoparticles with an average particle size of 18 $\mathrm{nm}$ were magnetically separated from the sediments and characterized using XRD, TEM, FTIR, SEM and EDX. Furthermore, in vitro synthesis of maghemite nanoparticles was carried out in the laboratory using the bacteria strain isolated from the saltpan sediment and similarly characterized. Toxicological studies carried out with varying nanoparticles dosage on Zebra fish embryo from the region showed developmental impairment and DNA damage. Increasing nanoparticles concentration correspondingly resulted in slower beat and hatching rate and increased mortality of Zebra fish eggs. These resulted in larvae malformation and proved that high concentration of maghemite nanoparticles in the region will have adverse effects on aquaculture.

\section{Challenges and future perspective}

However, there are certain drawbacks of nanoparticles biosynthesis.

a) Some researchers have argued on the side of food security, especially when fruits and vegetables are utilized during synthesis. Although this is a relatively recent field of study, some studies have reported the use of agro- and bio-waste as well as seaweeds and indigenous herbs. 
b) In some case, there is need to separate synthesized nanoparticle from biological material used.

c) The fate and transport of nanoparticles in the environment have not been extensively studied and understood.

d) The mechanism of reaction for nanoparticle synthesis is not fully understood presently. This is due to the diverse reactions between different biological agents and metal ion precursors leading to formation of nanoparticles with varying morphology. For instance, the mechanism for microorganism-based formation of nanoparticles is different with each biological agent (bacteria, fungi or yeast) for extracellular or intracellular methods. While electrostatic attraction between enzymes in the cell wall of microorganisms and metal ions leads to bioreduction during intracellular synthesis, electron transfer between enzymes and metal ions play a major role during extracellular synthesis.

e) Generation and treatment of nanowaste: Iron nanoparticles particularly zerovalent irons are highly reactive and are transferable from one medium to another. Waste generated from industries, if not properly disposed/treated can lead to contamination of groundwater, leading to transformation and interaction with soil microbes and fauna.

f) Toxicological effects.

g) More research is required to identify locally available eco-friendly sources of iron nanoparticles, particularly agrowaste.

h) Plant extracts of the same specie collected from different parts of the world and analyzed in different laboratories can give varying results. In some cases, different parts of the same plant material such as stem, leaf, bark and fruit give rise to formation of iron nanoparticles of varying morphology. There is need for more detailed study on the active biomolecules responsible for capping and stabilizing synthesized iron nanoparticles.

i) Nanoparticles synthesized by utilizing microorganisms are less stable, with longer reaction time, less yield and narrower morphological variation compared with other green-based methods. Further research in this area is needed by varying type of microorganism and substrate used to obtain uniform, crystalline and monodisperse nanoparticles.

j) Currently, there is absence of internationally accepted standardized methods for the synthesis of nanoparticles and incomprehensive characterization details, making it difficult to fully understand the mechanistic pathways for synthesis of these compounds. This has birthed the development of different methods for the synthesis of different nanoparticles, depending on the end user/researcher, without harmonization and global adoption of synthesis techniques. Consequently, there is inconsistency in research output and difficulty in predicting human health and environmental risk assessment of nanoparticles.

k) Life cycle impacts and detailed risk assessment of the production of iron nanoparticles has not been globally harmonized. This is of great essence as more engineered nanomaterials become commercially available by the day. For sustainable development, there is need for further studies of the net benefits of green-synthesized iron nanomaterials while considering potential human health and environmental impacts - from pre-production to commercialization, in comparison with conventional alternatives.

\section{Conclusion}

In this review, we have elaborated on greener techniques for the synthesis of iron-based nanomaterials such as the use of green plants, ionic liquids, microwave heating and microorganisms. In general, bioactive components of plant materials provide capping and stabilizing effects during synthesis thereby reducing nanoparticles growth and agglomeration. We have provided an up-to-date appraisal of the versatile applications of green-synthesized iron nanoparticles for environmental remediation and catalysis. There is growing research interest in the use of these eco-friendly materials for sorption of metal contaminants such as nickel, cadmium, chromium and lead, degradation of organic pollutants such as halogenated hydrocarbons, dyes, pesticides and pharmaceutical waste as well as heterogeneous catalysis. Surface modification of iron nanoparticles has helped in the synthesis of easily reusable magnetic nanoparticles, nanosorbents and nanocatalysts. Review of recent literature shows that considerably more work has been carried out using plant materials compared with microorganisms. Comparatively, plant-mediated synthesis is less hazardous, faster and more scalable industrially unlike microbe-mediated processes, which require more aseptic conditions and cumbersome process of maintaining cell cultures. While microwave-assisted plant-mediated synthesis can be achieved within few minutes, microbe-dependent processes are much slower, taking up to several hours or even a few days. Additionally, there is a huge variety of plant species and parts which can be utilized such as fruits, stem, bark, leaves and whole plant of fruit trees, herbs, medicinal plants, algae and seaweeds. Microbebased synthesis also offers lower yield and limited variation in morphology of synthesized nanoparticles. These factors, coupled with the ease of accessibility of plant materials most likely accounts for the exponential research output within the last 5 years in area of plantmediated iron nanoparticle synthesis compared with other green-based methods. Despite these varied applications in wastewater treatment, catalysis, removal of organic and inorganic contaminants, there is need for further study to overcome some of the challenges in understanding subsurface mechanistic pathways, fate and transport of nanoparticles in the environment and their toxicological implications.

\section{Declaration of Competing Interest}

All the authors declare no conflict of interest.

\section{Appendix A. Supplementary data}

Supplementary material related to this article can be found, in the online version, at doi:https://doi.org/10.1016/j.enmm.2019.100279.

\section{References}

Abdeen, M., Sabry, S., Ghozlan, H., El-Gendy, A.A., Carpenter, E.E., 2016. Microbialphysical synthesis of $\mathrm{Fe}$ and $\mathrm{Fe}_{3} \mathrm{O}_{4}$ magnetic nanoparticles using Aspergillus niger YESM1 and supercritical condition of ethanol. J. Nanomater. 2016, 1-7. https://doi. org/10.1155/2016/9174891.

Abdelghany, T.M., Al-rajhi, A.M.H., Abboud, M.A.A., 2017. Recent advances in green synthesis of silver nanoparticles and their applications: about future directions. A review. BioNanoSci. https://doi.org/10.1007/s12668-017-0413-3.

Abujaber, F., Zougagh, M., Jodeh, S., Ríos, Á., Javier, F., Bernardo, G., Martín-doimeadios, R.C.R., 2018. Magnetic cellulose nanoparticles coated with ionic liquid as a new material for the simple and fast monitoring of emerging pollutants in waters by magnetic solid phase extraction. Microchem. J. 137, 490-495. https://doi.org/10. 1016/j.microc. 2017.12.007.

Adil, F.S., Assal, E.M., Khan, M., Al-Warthana, A., Siddiquia, M.H.R., Liz-Marzán, M.L., 2014. Biogenic synthesis of metallic nanoparticles and prospects toward green chemistry. J. Chem. Soc. Dalton Trans. 8439-8445. https://doi.org/10.1039/ c3dt53561d.

Afsheen, S., Bilal, M., Iqbal, T., Liaqat, A., Abrar, M., 2018. Green synthesis and characterization of novel iron particles by using different extracts. J. Alloys Compd. 732, 935-944. https://doi.org/10.1016/j.jallcom.2017.10.137.

Ahmed, F., Arshi, N., Anwar, M.S., Danish, R., Koo, B.H., 2014a. Quantum-confinement induced enhancement in photocatalytic properties of iron oxide nanoparticles prepared by ionic liquid. Ceram. Int. 40 (10), 15743-15751. https://doi.org/10.1016/j. ceramint.2014.07.098.

Ahmed, S., Ahmad, M., Swami, B.L., Ikram, S., 2016. A review on plants extract mediated synthesis of silver nanoparticles for antimicrobial applications: a green expertise. J. Adv. Res. 7 (1), 17-28. https://doi.org/10.1016/j.jare.2015.02.007.

Ahmed, S., Annu, Chaudhry, S.A., Ikram, S., 2017. A review on biogenic synthesis of ZnO nanoparticles using plant extracts and microbes: a prospect towards green chemistry. J. Photochem. Photobiol. B Biol. 166, 272-284. https://doi.org/10.1016/j. jphotobiol.2016.12.011.

Ahmed, T., Imdad, S., Yaldram, K., Butt, N.M., Pervez, A., 2014b. Emerging nanotechnology-based methods for water purification: a review. Desalin. Water Treat. 52 (22-24), 4089-4101. https://doi.org/10.1080/19443994.2013.801789.

Al-Ruqeishi, M.S., Mohiuddin, T., Al-Saadi, L.K., 2016. Green synthesis of iron oxide nanorods from deciduous Omani mango tree leaves for heavy oil viscosity treatment. 
Arab. J. Chem. https://doi.org/10.1016/j.arabjc.2016.04.003.

Ali, I., Alothman, Z.A., Alwarthan, A., 2017. Uptake of propranolol on ionic liquid iron nanocomposite adsorbent: kinetic, thermodynamics and mechanism of adsorption. J. Mol. Liq. 236https://doi.org/10.1016/j.molliq.2017.04.028. Elsevier B.V.

Ali, K., Dwivedi, S., Azam, A., Saquib, Q., Al-said, M.S., Alkhedhairy, A.A., Musarrat, J., 2016. Aloe vera extract functionalized zinc oxide nanoparticles as nanoantibiotics against multi-drug resistant clinical bacterial isolates. J. Colloid Interface Sci. 472, 145-156. https://doi.org/10.1016/j.jcis.2016.03.021.

Ali, S., Aziz, S., Rehman, U., Luan, H., Usman, M., Huang, H., 2019. Environment Challenges and opportunities in functional carbon nanotubes for membrane-based water treatment and desalination. Sci. Total Environ. 646 (19), 1126-1139. https:// doi.org/10.1016/j.scitotenv.2018.07.348.

Allard-vannier, E., Hervé-aubert, K., Kaaki, K., Blondy, T., Shebanova, A., Shaitan, K.V., et al., 2017. Folic acid-capped PEGylated magnetic nanoparticles enter cancer cells mostly via clathrin-dependent endocytosis. BBA Gen. Subjects 1861 (6), 1578-1586. https://doi.org/10.1016/j.bbagen.2016.11.045.

Alvarez-romero, G.A., Alberto, A., Mendoza-tolentino, Y., Contreras-1, E., María, E.P., Gal, C.A., 2018. Optimization of microwave-solvothermal synthesis of $\mathrm{Fe}_{3} \mathrm{O}_{4}$ nanoparticles. Coating, modification, and characterization. Mater. Chem. Phys. 205, 113-119. https://doi.org/10.1016/j.matchemphys.2017.11.009.

Amores, M., Ashton, T.E., Baker, P.J., Cussen, J., Corr, S.A., 2016. Fast microwave-assisted synthesis of Li-stuffed garnets and insights into Li diffusion from muon spin spectroscopy. J. Mater. Chem. A Mater. Energy Sustain. 4, 1729-1736. https://doi. org/10.1039/C5TA08107F.

Anastas, P.T., Werner, J.C., 1998. Green Chemistry: Theory and Practice. Oxford University Press, New York.

Arumugam, V., Sriram, P., Yen, T., Govindsamy, G., Moonsamy, R., 2018. Environmental Nano-material as an excellent catalyst for reducing a series of nitroanilines and dyes: triphosphonated ionic liquid- $\mathrm{CuFe}_{2} \mathrm{O}_{4}$-modified boron nitride. Appl. Catal. B 222, 99-114. https://doi.org/10.1016/j.apcatb.2017.08.059.

Atarod, M., Nasrollahzadeh, M., Mohammad Sajadi, S., 2016. Green synthesis of Pd/ $\mathrm{RGO} / \mathrm{Fe}_{3} \mathrm{O}_{4}$ nanocomposite using Withania coagulans leaf extract and its application as magnetically separable and reusable catalyst for the reduction of 4-nitrophenol. J. Colloid Interface Sci. 465, 249-258. https://doi.org/10.1016/j.jcis.2015.11.060.

Basavegowda, N., Mishra, K., Lee, Y.R., 2017. Trimetallic FeAgPt alloy as a nanocatalyst for the reduction of 4-nitroaniline and decolorization of rhodamine B: a comparative study. J. Alloys. Compd. 701, 456-464. https://doi.org/10.1016/j.jallcom.2017.01. 122.

Bishnoi, S., Kumar, A., Selvaraj, R., 2017. Facile synthesis of magnetic iron oxide nanoparticles using inedible Cynometra ramiflora fruit extract waste and their photocatalytic degradation of methylene blue dye. Mater. Res. Bull. 97, 121-127. https:// doi.org/10.1016/j.materresbull.2017.08.040.

Bolade, O.P., Akinsiku, A.A., Adeyemi, A.O., Williams, A.B., Benson, N.U., 2018. Dataset on phytochemical screening, FTIR and GC-MS characterisation of Azadirachta indica and Cymbopogon citratus as reducing and stabilising agents for nanoparticles synthesis. Data Brief. https://doi.org/10.1016/j.dib.2018.08.133.

Bolade, O.P., Akinsiku, A.A., Adeyemi, A.O., Jolayemi, G.E., Williams, A.B., Benson, N.U., 2019. Qualitative analysis, total phenolic content, FT-IR and GC- MS characterisation of Canna indica: bioreducing agent for nanoparticles synthesis. J. Phys. Conf. Ser. 129, 012135. https://doi.org/10.1088/1742-6596/1299/1/012135.

Borja, J.Q., Ngo, M.A.S., Saranglao, C.C., Tiongco, R.P.M., Roque, E.C., Dugos, N.P., 2015. Synthesis of green zero-valent iron using polyphenols from dried green tea extract. J. Eng. Sci. Technol. 10 (Spec.issue7), 22-31.

Cao, D., Jin, X., Gan, L., Wang, T., Chen, Z., 2016. Removal of phosphate using iron oxide nanoparticles synthesized by eucalyptus leaf extract in the presence of CTAB surfactant. Chemosphere 159, 23-31. https://doi.org/10.1016/j.chemosphere.2016.05. 080 .

Carenza, E., Barceló, V., Morancho, A., Montaner, J., Rosell, A., Roig, A., 2014. Rapid synthesis of water-dispersible superparamagnetic iron oxide nanoparticles by a microwave-assisted route for safe labeling of endothelial progenitor cells. Acta Biomater. 10 (8), 3775-3785. https://doi.org/10.1016/j.actbio.2014.04.010.

Carrillo, A.I., Serrano, E., Luque, R., García-Martínez, J., 2013. Microwave-assisted catalysis by iron oxide nanoparticles on MCM-41: effect of the support morphology. Appl. Catal. A Gen. 453, 383-390. https://doi.org/10.1016/j.apcata.2012.12.041.

Chen, F., Xie, S., Huang, X., Qiu, X., 2015. Ionothermal synthesis of $\mathrm{Fe}_{3} \mathrm{O}_{4}$ magnetic nanoparticles as efficient heterogeneous Fenton-like catalysts for degradation of organic pollutants with $\mathrm{H}_{2} \mathrm{O}_{2}$. J. Hazard. Mater. 322, 152-162. https://doi.org/10. 1016/j.jhazmat.2016.02.073.

Chen, J., Zhu, X., 2016. Magnetic solid phase extraction using ionic liquid-coated coreshell magnetic nanoparticles followed by high-performance liquid chromatography for determination of Rhodamine B in food samples. Food Chem. 200, 10-15. https:/ doi.org/10.1016/j.foodchem.2016.01.002.

Darroudi, M., Ahmad, M.B., Zamiri, R., Zak, A.K., Abdullah, A.H., Ibrahim, N.A., 2011. Time-dependent effect in green synthesis of silver nanoparticles. Int. J. Nanomed. 6, $677-681$.

Das, K.R., Kowshik, M., Praveen Kumar, M.K., Kerkar, S., Shyama, S.K., Mishra, S., 2018. Native hypersaline sulphate reducing bacteria contributes to iron nanoparticle formation in saltpan sediment: a concern for aquaculture. J. Environ. Manage. 206, 556-564. https://doi.org/10.1016/j.jenvman.2017.10.078.

Devatha, C.P., Jagadeesh, K., Patil, M., 2018. Effect of Green synthesized iron nanoparticles by Azardirachta Indica in different proportions on antibacterial activity. Environ. Nanotechnol. Monit. Manag. 9, 85-94. https://doi.org/10.1016/j.enmm. 2017.11.007.

Ebrahiminezhad, A., Taghizadeh, S., Ghasemi, Y., Berenjian, A., 2017. Green synthesized nanoclusters of ultra-small zero valent iron nanoparticles as a novel dye removing material. Sci. Total Environ. https://doi.org/10.1016/j.scitotenv.2017.10.076.
Ehrampoush, M.H., Miria, M., Salmani, M.H., Mahvi, A.H., 2015. Cadmium removal from aqueous solution by green synthesis iron oxide nanoparticles with tangerine peel extract. J. Environ. Health Sci. Eng. 13 (1), 84. https://doi.org/10.1186/s40201-0150237-4.

El-Seedi, H.R., El-Shabasy, R.M., Khalifa, S.A.M., Saeed, A., Shah, A., Shah, R., Iftikhar, F.J., Abdel-Daim, M.M., Omri, A., Hajrahand, N.H., Sabir, J.S., Zou, X., Halabi, M.F., Sarhann, W., Guo, W., 2019. Metal nanoparticles fabricated by green chemistry using natural extracts: biosynthesis, mechanisms, and applications. RSC Adv. 9, 24539-24559. https://doi.org/10.1039/C9RA02225B.

Es'haghi, Z., Vafaeinezhad, F., Hooshmand, S., 2016. Green synthesis of magnetic iron nanoparticles coated by olive oil and verifying its efficiency in extraction of nickel from environmental samples via UV-vis spectrophotometry. Process. Saf. Environ. Prot. 102, 403-409. https://doi.org/10.1016/j.psep.2016.04.011.

Fang, L., Xu, C., Zhang, W., Huang, L., 2018. The important role of polyvinylpyrrolidone and $\mathrm{Cu}$ on enhancing dechlorination of 2,4-dichlorophenol by $\mathrm{Cu} / \mathrm{Fe}$ nanoparticles performance and mechanism study. Appl. Surf. Sci. 435, 55-64. https://doi.org/10. 1016/j.apsusc.2017.11.084.

Farzad, E., Veisi, H., 2017. Chemistry $\mathrm{Fe}_{3} \mathrm{O}_{4} / \mathrm{SiO}_{2}$ nanoparticles coated with polydopamine as a novel magnetite reductant and stabilizer sorbent for palladium ions: synthetic application of $\mathrm{Fe}_{3} \mathrm{O}_{4} / \mathrm{SiO}_{2} @ \mathrm{PDA} / \mathrm{Pd}$ for reduction of 4-nitrophenol and Suzuki reactions. J. Ind. Eng. Chem. https://doi.org/10.1016/j.jiec.2017.10.017.

Fawcett, D., Verduin, J.J., Shah, M., Sharma, S.B., Eddy, G., Poinern, J., 2017. A review of current research into the biogenic synthesis of metal and metal oxide nanoparticles via marine algae and seagrasses. J. Nanosci. 2017, 1-15. https://doi.org/10.1155/ 2017/8013850.

Fazlzadeh, M., Ansarizadeh, M., Leili, M., 2018. Data of furfural adsorption on nano zero valent iron (NZVI) synthesized from Nettle extract. Data Brief 16, 341-345. https:// doi.org/10.1016/j.dib.2017.11.035.

Fazlzadeh, M., Rahmani, K., Zarei, A., Abdoallahzadeh, H., Nasiri, F., Khosravi, R., 2017. A novel green synthesis of zero valent iron nanoparticles (NZVI) using three plant extracts and their efficient application for removal of $\mathrm{Cr}$ (VI) from aqueous solutions. Adv. Powder Technol. 28 (1), 122-130. https://doi.org/10.1016/j.apt.2016.09.003.

Gan, L., Lu, Z., Cao, D., Chen, Z., 2018. Effects of cetyltrimethylammonium bromide on the morphology of green synthesized $\mathrm{Fe}_{3} \mathrm{O}_{4}$ nanoparticles used to remove phosphate. Mater. Sci. Eng. C 82, 41-45. https://doi.org/10.1016/j.msec.2017.08.073.

Gilbertson, L.M., Zimmerman, J.B., Plata, D.L., Hutchison, J.E., Anastas, P.T., 2015. Designing nanomaterials to maximize performance and minimize undesirable implications guided by the Principles of Green Chemistry. Chem. Soc. Rev. 44 (16), 5758-5777. https://doi.org/10.1039/C4CS00445K.

Gonzalez-Moragas, L., Yu, S.-M., Murillo-Cremaes, N., Laromaine, A., Roig, A., 2015. Scale-up synthesis of iron oxide nanoparticles by microwave-assisted thermal decomposition. Chem. Eng. J. 281, 87-95. https://doi.org/10.1016/j.cej.2015.06.066.

Grindi, B., Beji, Z., Viau, G., BenAli, A., 2018. Microwave-assisted synthesis and magnetic

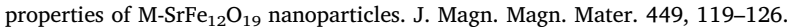
https://doi.org/10.1016/j.jmmm.2017.10.002.

Groiss, S., Selvaraj, R., Varadavenkatesan, T., Vinayagam, R., 2017. Structural characterization, antibacterial and catalytic effect of iron oxide nanoparticles synthesised using the leaf extract of Cynometra ramiflora. J. Mol. Struct. 1128, 572-578. https:// doi.org/10.1016/j.molstruc.2016.09.031.

Guo, M., Weng, X., Wang, T., Chen, Z., 2017. Biosynthesized iron-based nanoparticles used as a heterogeneous catalyst for the removal of 2,4-dichlorophenol. Sep. Purif. Technol. 175, 222-228. https://doi.org/10.1016/j.seppur.2016.11.042.

He, H., Yuan, D., Gao, Z., Xiao, D., He, H., Dai, H., et al., 2014. Mixed hemimicelles solidphase extraction based on ionic liquid-coated $\mathrm{Fe}_{3} \mathrm{O}_{4} / \mathrm{SiO}_{2}$ nanoparticles for the determination of flavonoids in bio-matrix samples coupled with high performance liquid chromatography. J. Chromatogr. A 1324, 78-85. https://doi.org/10.1016/j. chroma.2013.11.021.

Huang, L., Luo, F., Chen, Z., Megharaj, M., Naidu, R., 2015. Green synthesized conditions impacting on the reactivity of Fe NPs for the degradation of malachite green. Spectrochim. Acta A. Mol. Biomol. Spectrosc. 137, 154-159. https://doi.org/10. 1016/j.saa.2014.08.116.

Huang, X., Xu, C., Ma, J., Chen, F., 2018. Ionothermal synthesis of Cu-doped $\mathrm{Fe}_{3} \mathrm{O}_{4}$ magnetic nanoparticles with enhanced peroxidase-like activity for organic wastewater treatment. Adv. Powder Technol.(January). https://doi.org/10.1016/j.apt. 2017.12.025.

Hulkoti, N.I., Taranath, T.C., 2014. Biosynthesis of nanoparticles using microbes - a review. Colloids Surf. B Biointerfaces. https://doi.org/10.1016/j.colsurfb.2014.05.027.

Iqbal, A., Iqbal, K., Li, B., Gong, D., Qin, W., 2017. Recent advances in Iron nanoparticles: preparation, properties, biological and environmental application. J. Nanosci. Nanotechnol. 17 (7), 4386-4409. https://doi.org/10.1166/jnn.2017.14196.

Isaad, J., El, A., 2018. Synthesis and spectroscopic characterization of azoic dyes based on pyrazolone derivatives catalyzed by an acidic ionic liquid supported on silica-coated magnetite nanoparticle. J. Mol. Struct. 1154, 557-564. https://doi.org/10.1016/j molstruc.2017.10.091.

Ivashchenko, O., Gapi, J., Pepli, B., Przysiecka, Ł., Zalewski, T., Nowaczyk, G., et al., 2017. Self-organizing silver and ultrasmall iron oxide nanoparticles prepared with ginger rhizome extract: characterization, biomedical potential and microstructure analysis of hydrocolloids. Mater. Des. 133, 307-324. https://doi.org/10.1016/j. matdes.2017.08.001.

Jagathesan, G., Rajiv, P., 2018. Biosynthesis and characterization of iron oxide nanoparticles using Eichhornia crassipes leaf extract and assessing their antibacterial ac tivity. Biocatal. Agric. Biotechnol. 13, 90-94. https://doi.org/10.1016/j.bcab.2017. 11.014.

Jassal, V., Shanker, U., Gahlot, S., 2016. Green synthesis of some iron oxide nanoparticles and their interaction with 2-Amino, 3-Amino and 4-Aminopyridines. Mater. Today Proc. 3 (6), 1874-1882. https://doi.org/10.1016/j.matpr.2016.04.087. 
Jin, X., Liu, Y., Tan, J., Owens, G., Chen, Z., 2017. Removal of Cr(VI) from aqueous solutions via reduction and absorption by green synthesized iron nanoparticles. J. Clean. Prod. https://doi.org/10.1016/j.jclepro.2017.12.026.

Kania, G., Sternak, M., Jasztal, A., Chlopicki, S., Agnieszka, B., Nasulewicz-goldeman, A., et al., 2018. Uptake and bioreactivity of charged chitosan-coated superparamagnetic nanoparticles as promising contrast agents for magnetic resonance imaging. Nanomed. Nanotechnol. Biol. Med. 14, 131-140. https://doi.org/10.1016/j.nano. 2017.09.004.

Karpagavinayagam, P., Vedhi, C., 2019. Green synthesis of iron oxide nanoparticles using Avicennia marina flower extract. Vacuum 160, 286-292. https://doi.org/10.1016/j. vacuum.2018.11.043.

Katata-Seru, L., Moremedi, T., Aremu, O.S., Bahadur, I., 2017. Green synthesis of iron nanoparticles using Moringa oleifera extracts and their applications: removal of nitrate from water and antibacterial activity against Escherichia coli. J. Mol. Liq. https://doi.org/10.1016/j.molliq.2017.11.093.

Kaul, R.K., Kumar, P., Burman, U., Joshi, P., Agrawal, A., Raliya, R., Tarafdar, J.C., 2012. Magnesium and iron nanoparticles production using microorganisms and various salts. Mater. Sci. Poland 30 (3), 254-258. https://doi.org/10.2478/s13536-0120028-x.

Khalil, A.T., Ovais, M., Ullah, I., Ali, M., Khan Shinwari, Z., Maaza, M., 2017. Biosynthesis of iron oxide $\left(\mathrm{Fe}_{2} \mathrm{O}_{3}\right)$ nanoparticles via aqueous extracts of Sageretia thea (Osbeck.) and their pharmacognostic properties. Green Chem. Lett. Rev. 10 (4), 186-201. https://doi.org/10.1080/17518253.2017.1339831.

Kharissova, O.V., Dias, H.V.R., Kharisov, B.I., Pérez, B.O., Pérez, V.M.J., 2013. The greener synthesis of nanoparticles. Trends Biotechnol. 31 (4), 240-248. https://doi. org/10.1016/j.tibtech.2013.01.003.

Khatami, M., Alijani, H.Q., Fakheri, B., Mobasseri, M.M., Heydarpour, M., Farahani, Z.K., Ullah, A., 2019. Super-paramagnetic iron oxide nanoparticles (SPIONs): greener synthesis using Stevia plant and evaluation of its antioxidant properties. J. Clean. Prod. 208, 1171-1177. https://doi.org/10.1016/j.jclepro.2018.10.182.

Kombaiah, K., Vijaya, J.J., Kennedy, L.J., Bououdina, M., 2017a. Optical, magnetic and structural properties of $\mathrm{ZnFe}_{2} \mathrm{O}_{4}$ nanoparticles synthesized by conventional and microwave assisted combustion method: a comparative investigation. Opt. - Int. J. Light Electron. Opt. 129, 57-68. https://doi.org/10.1016/j.ijleo.2016.10.058.

Kombaiah, K., Vijaya, J.J., Kennedy, L.J., Bououdina, M., Al-najar, B., 2018a. Conventional and microwave combustion synthesis of optomagnetic $\mathrm{CuFe}_{2} \mathrm{O}_{4}$ nanoparticles for hyperthermia studies. J. Phys. Chem. Solids 115, 162-171. https://doi. org/10.1016/j.jpcs.2017.12.024.

Kombaiah, K., Vijaya, J.J., Kennedy, L.J., Bououdina, M., Ramalingam, R.J., Al-Lohedan, H.A., 2017b. Okra extract-assisted green synthesis of $\mathrm{CoFe}_{2} \mathrm{O}_{4}$ nanoparticles and their optical, magnetic, and antimicrobial properties. Mater. Chem. Phys. 204, 410-419. https://doi.org/10.1016/j.matchemphys.2017.10.077.

Krishna, R., Dias, C., Ventura, J., Titus, E., 2016. Green and facile decoration of Fe $3 \mathrm{O}_{4}$ nanoparticles on reduced graphene oxide. Mater. Today Proc. 3 (8), 2807-2813. https://doi.org/10.1016/j.matpr.2016.06.030.

Kuchibhatla, S.V., Karakoti, A.S., Baer, D.R., et al., 2012. Influence of aging and environment on nanoparticle chemistry: implication to confinement effects in nanoceria. J. Phys. Chem. C 116, 14108-14114.

Kumar, B., Smita, K., Cumbal, L., Debut, A., 2014. Biogenic synthesis of iron oxide nanoparticles for 2-arylbenzimidazole fabrication. J. Saudi Chem. Soc. 18 (4), 364-369. https://doi.org/10.1016/j.jscs.2014.01.003.

Lakshmi, P.P., Krishna, M.G., Venkateswara, R.K., Shanker, K., 2019. Biosynthesis, characterization and acute oral toxicity studies of synthesised iron oxide nanoparticles using ethanolic extract of Centella asiatica plant. Mater. Lett. 236, 256-259. https://doi.org/10.1016/j.matlet.2018.10.037.

Lastovina, T.A., Budnyk, A.P., Soldatov, M.A., Rusalev, Y.V., Guda, A.A., Bogdan, A.S., Soldatov, A.V., 2017. Microwave-assisted synthesis of magnetic iron oxide nanoparticles in oleylamine-oleic acid solutions. Mendeleev Commun. 27 (5), 487-489. https://doi.org/10.1016/j.mencom.2017.09.019.

Li, A.Y., Kaushik, M., Li, C.J., Moores, A., 2016. Microwave-assisted synthesis of magnetic carboxymethyl cellulose-embedded Ag-Fe3O4 nanocatalysts for selective carbonyl hydrogenation. ACS Sustain. Chem. Eng. 4 (3), 965-973. https://doi.org/10.1021/ acssuschemeng.5b01048.

Li, J., Hu, J., Xiao, L., Wang, Y., Wang, X., 2018. Interaction mechanisms between $\alpha$ $\mathrm{Fe}_{2} \mathrm{O}_{3}, \gamma-\mathrm{Fe}_{2} \mathrm{O}_{3}$ and $\mathrm{Fe}_{3} \mathrm{O}_{4}$ nanoparticles and Citrus maxima seedlings. Sci. Total Environ. 625, 677-685. https://doi.org/10.1016/j.scitotenv.2017.12.276.

Liang, J., Zhuo, M., Guo, D., Chen, Z., Ren, W., Zhang, M., Li, Q., 2016. Green and rapid synthesis of 3D Fe $2\left(\mathrm{MoO}_{4}\right)_{3}$ by microwave irradiation to detect $\mathrm{H}_{2} \mathrm{~S}$ gas. Mater. Lett. 168 (3), 171-175. https://doi.org/10.1016/j.matlet.2016.01.048.

Liang, Y., Fan, F., Ma, M., Sun, J., Chen, J., Zhang, Y., 2017. Size-dependent electromagnetic properties and the related simulations of $\mathrm{Fe}_{3} \mathrm{O}_{4}$ nanoparticles made by microwave-assisted thermal decomposition. Colloids Surf. A Physicochem. Eng. Asp. 530, 191-199. https://doi.org/10.1016/j.colsurfa.2017.06.059.

Lin, K., Mdlovu, N.V., Chen, C., Chiang, C., 2018. Degradation of TCE, PCE, and 1,2e DCE DNAPLs in contaminated groundwater using polyethylenimine-modified zero-valent iron nanoparticles. J. Clean. Prod. 175, 456-466. https://doi.org/10.1016/j.jclepro. 2017.12.074.

Lin, R., Li, Y., Macdonald, T., Wu, H., Provenzale, J., Peng, X., et al., 2017. Biointerfaces improving sensitivity and specificity of capturing and detecting targeted cancer cells with anti-biofouling polymer coated magnetic iron oxide nanoparticles. Colloids Surf. B Biointerfaces 150, 261-270. https://doi.org/10.1016/j.colsurfb.2016.10.026.

Łuczak, J., Paszkiewicz, M., Krukowska, A., Malankowska, A., Zaleska-Medynska, A., 2016b. Ionic liquids for nano- and microstructures preparation. Part 2: application in synthesis. Adv. Colloid Interface Sci. 227, 1-52. https://doi.org/10.1016/j.cis.2015. 08.010 .

Luo, F., Yang, D., Chen, Z., Megharaj, M., Naidu, R., 2016. One-step green synthesis of bimetallic Fe / Pd nanoparticles used to degrade Orange II. J. Hazard. Mater. 303, 145-153. https://doi.org/10.1016/j.jhazmat.2015.10.034.

Machado, S., Grosso, J.P., Nouws, H.P.A., Albergaria, J.T., 2014. Environment utilization of food industry wastes for the production of zero-valent iron nanoparticles. Sci. Total Environ. 496, 233-240. https://doi.org/10.1016/j.scitotenv.2014.07.058.

Machado, S., Pacheco, J.G., Nouws, H.P.A., Albergaria, J.T., Delerue-Matos, C., 2017. Green zero-valent iron nanoparticles for the degradation of amoxicillin. Int. J. Environ. Sci. Technol. 14 (5), 1109-1118. https://doi.org/10.1007/s13762-0161197-7.

Machado, S., Pinto, S.L., Grosso, J.P., Nouws, H.P.A., Albergaria, J.T., Delerue-Matos, C., 2013a. Green production of zero-valent iron nanoparticles using tree leaf extracts. Sci. Total Environ. 445-446, 1-8. https://doi.org/10.1016/j.scitotenv.2012.12.033.

Machado, S., Stawiński, W., Slonina, P., Pinto, A.R., Grosso, J.P., Nouws, H.P.A., et al., 2013b. Application of green zero-valent iron nanoparticles to the remediation of soils contaminated with ibuprofen. Sci. Total Environ. 461-462, 323-329. https://doi. org /10.1016/j.scitotenv.2013.05.016.

Madhubala, V., Kalaivani, T., 2017. Phyto and hydrothermal synthesis of $\mathrm{Fe}_{3} \mathrm{O}_{4} @ \mathrm{ZnO}$ core-shell nanoparticles using Azadirachta indica and its cytotoxicity studies. Appl. Surf. Sci. https://doi.org/10.1016/j.apsusc.2017.12.105.

Mahmoud, M.E., Amira, M.F., Zaghloul, A.A., Ibrahim, G.A.A., 2016a. High performance microwave-enforced solid phase extraction of heavy metals from aqueous solutions using magnetic iron oxide nanoparticles-protected-nanosilica. Sep. Purif. Technol. 163, 169-172. https://doi.org/10.1016/j.seppur.2016.02.039.

Mahmoud, M.E., Amira, M.F., Zaghloul, A.A., Ibrahim, G.A.A., 2016b. Microwave-enforced sorption of heavy metals from aqueous solutions on the surface of magnetic iron oxide-functionalized-3-aminopropyltriethoxysilane. Chem. Eng. J. 293, 200-206. https://doi.org/10.1016/j.cej.2016.02.056.

Manatunga, D.C., Silva, R.M.D., Silva, K.M.N.D., Silva, N.D., Bhandari, S., Khin, Y., Costha, N.P., 2017. pH responsive controlled release of anti-cancer hydrophobic drugs from sodium alginate and hydroxyapatite bi-coated iron oxide nanoparticles. Eur. J. Pharm. Biopharm. 117, 29-38. https://doi.org/10.1016/j.ejpb.2017.03.014.

Manquián-Cerda, K., Cruces, E., Angélica Rubio, M., Reyes, C., Arancibia-Miranda, N., 2017. Preparation of nanoscale iron (oxide, oxyhydroxides and zero-valent) particles derived from blueberries: reactivity, characterization and removal mechanism of arsenate. Ecotoxicol. Environ. Saf. 145, 69-77. https://doi.org/10.1016/j.ecoenv. 2017.07.004.

Marimón-Bolívar, W., González, E.E., 2018. Green synthesis with enhanced magnetization and life cycle assessment of $\mathrm{Fe}_{3} \mathrm{O}_{4}$ nanoparticles. Environ. Nanotechnol. Monit. Manage. 9, 58-66. https://doi.org/10.1016/j.enmm.2017.12.003.

Mazumdar, H., Haloi, N., 2011. A study on biosynthesis of iron nanoparticles by Pleurotus sp. J. Microbiol. Biotech. Res. 1 (3), 39-49. https://doi.org/10.1155/2010/745120.

Mehrotra, N., Tripathi, R.M., Zafar, F., Singh, M.P., 2017. Catalytic degradation of dichlorvos using biosynthesized zero valent Iron nanoparticles. IEEE Trans. Nanobiosci. 16 (4), 280-286. https://doi.org/10.1109/TNB.2017.2700232.

Mishra, K., Basavegowda, N., Lee, Y.R., 2015. General AuFeAg hybrid nanoparticles as an efficient recyclable catalyst for the synthesis of a,B- and B,B-dichloroenones. Appl. Catal. A Gen. 506, 180-187. https://doi.org/10.1016/j.apcata.2015.09.014.

Mohan Kumar, K., Mandal, B.K., Siva Kumar, K., Sreedhara Reddy, P., Sreedhar, B., 2013. Biobased green method to synthesise palladium and iron nanoparticles using Terminalia chebula aqueous extract. Spectrochim. Acta - Part A 102, 128-133. https://doi.org/10.1016/j.saa.2012.10.015.

Mondal, P., Purkait, M.K., 2018. Green synthesized iron nanoparticles supported on pH responsive polymeric membrane for nitrobenzene reduction and fluoride rejection study: optimization approach. J. Clean. Prod. 170, 1111-1123. https://doi.org/10. 1016/j.jclepro. 2017.09.222.

Mukherjee, P., 2017. Stenotrophomonas and Microbacterium: mediated biogenesis of copper, silver and iron nanoparticles-proteomic insights and antibacterial properties versus biofilm formation. J. Clust. Sci. 28, 331-358. https://doi.org/10.1007/ s10876-016-1097-5.

Nasrollahzadeh, M., Atarod, M., Sajjadi, S.M., 2017. Biosynthesis, characterization and catalytic activity of $\mathrm{Cu} / \mathrm{RGO} / \mathrm{Fe}_{3} \mathrm{O}_{4}$ for direct cyanation of aldehydes with $\mathrm{K}_{4}$ [Fe $\left.(\mathrm{CN})_{6}\right]$. J. Colloid Interface Sci. 486, 153-162. https://doi.org/10.1016/j.jcis.2016. 09.053.

Natarajan, E., Ponnaiah, G.P., 2017. Optimization of process parameters for the decolorization of Reactive Blue 235 dye by barium alginate immobilized iron nanoparticles synthesized from aluminum industry waste. Environ. Nanotechnol. Monit. Manage. 7, 73-88. https://doi.org/10.1016/j.enmm.2017.01.002.

Nisticò, R., Cesano, F., Franzoso, F., Magnacca, G., Scarano, D., Funes, I.G., et al., 2018 From biowaste to magnet-responsive materials for water remediation from polycyclic aromatic hydrocarbons. Chemosphere 202, 686-693. https://doi.org/10.1016/j chemosphere. 2018.03.153.

Nithya, K., Sathish, A., Senthil Kumar, P., Ramachandran, T., 2017. Fast kinetics and high adsorption capacity of green extract capped superparamagnetic iron oxide nanoparticles for the adsorption of Ni(II) ions. J. Ind. Eng. Chem. https://doi.org/10. 1016/j.jiec.2017.10.028.

Nosrati, H., Sefidi, N., Sharafi, A., Danafar, H., Kheiri, H., 2018. Bovine Serum Albumin (BSA) coated iron oxide magnetic nanoparticles as biocompatible carriers for curcumin-anticancer drug. Bioorg. Chem. 76, 501-509. https://doi.org/10.1016/j. bioorg. 2017.12.033.

Olajire, A.A., Ifediora, N.F., Bello, M.D., Benson, N.U., 2017a. Green synthesis of copper nanoparticles using Alchornea laxiflora leaf extract and their catalytic application for oxidative desulphurization of model oil. Iran. J. Sci. Technol. Trans. A Sci. 9. https:// doi.org/10.1007/s40995-017-0404-9.

Olajire, A.A., Abidemi, J.J., Lateef, A., Benson, N.U., 2017b. Adsorptive desulphurization of model oil by Ag nanoparticles-modified activated carbon prepared from brewer's spent grains. J. Environ. Chem. Eng. 5 (2017), 147-159. https://doi.org/10.1016/j. 
jece.2016.11.033

Ortega, D., Southern, P., Pankhurst, Q.A., Thanh, N.T.K., 2015. High performance multicore iron oxide nanoparticles for magnetic hyperthermia: microwave synthesis, and the role of core-to-core. Nanoscale 7, 1768-1775. https://doi.org/10.1039/ c4nr06239f.

Ostovan, A., Ghaedi, M., Arabi, M., 2018. Fabrication of water-compatible superparamagnetic molecularly imprinted biopolymer for clean separation of baclofen from bio- fluid samples: a mild and green approach. Talanta 179, 760-768. https:// doi.org/10.1016/j.talanta.2017.12.017.

Park, T.J., Lee, K.G., Lee, S.Y., 2016. Advances in microbial biosynthesis of metal nanoparticles. Appl. Microbiol. Biotechnol. 100 (2), 521-534. https://doi.org/10.1007/ s00253-015-6904-7.

Patra, J.K., Baek, K.-H., 2017. Green biosynthesis of magnetic iron oxide $\left(\mathrm{Fe}_{3} \mathrm{O}_{4}\right)$ nanoparticles using the aqueous extracts of food processing wastes under photo-catalyzed condition and investigation of their antimicrobial and antioxidant activity. J. Photochem. Photobiol. B, Biol. 173, 291-300. https://doi.org/10.1016/j.jphotobiol. 2017.05.045.

Patra, J.K., Baek, K.-H., 2014. Green Nanobiotechnology: factors affecting synthesis and characterization techniques. J. Nanomater. 2014https://doi.org/10.1155/2014/ 417305. Article ID 417305.

Prabhakar, R., Samadder, S.R., 2017. Aquatic and terrestrial weed mediated synthesis of iron nanoparticles for possible application in wastewater remediation. J. Clean. Prod. 168, 1201-1210. https://doi.org/10.1016/j.jclepro.2017.09.063.

Prabhakar, R., Samadder, S.R., Jyotsana, 2017. Aquatic and terrestrial weed mediated synthesis of iron nanoparticles for possible application in wastewater remediation. J. Clean. Prod. 168, 1201-1210. https://doi.org/10.1016/j.jclepro.2017.09.063.

Prasad, A.S., 2016. Iron oxide nanoparticles synthesized by controlled bio-precipitation using leaf extract of Garlic Vine (Mansoa alliacea). Mater. Sci. Semicond. Process. 53, 79-83. https://doi.org/10.1016/j.mssp.2016.06.009.

Prasad, C., Karlapudi, S., Venkateswarlu, P., Bahadur, I., Kumar, S., 2017a. Green arbitrated synthesis of $\mathrm{Fe}_{3} \mathrm{O}_{4}$ magnetic nanoparticles with nanorod structure from pomegranate leaves and Congo red dye degradation studies for water treatment. J. Mol. Liq. 240, 322-328. https://doi.org/10.1016/j.molliq.2017.05.100.

Prasad, C., Krishna Murthy, P., Hari Krishna, R.H., Sreenivasa Rao, R., Suneetha, V., Venkateswarlu, P., 2017b. Bio-inspired green synthesis of $\mathrm{RGO} / \mathrm{Fe}_{3} \mathrm{O}_{4}$ magnetic nanoparticles using Murrayakoenigii leaves extract and its application for removal of $\mathrm{Pb}$ (II) from aqueous solution. J. Environ. Chem. Eng. 5 (5). https://doi.org/10.1016/j. jece.2017.07.026.

Prasad, C., Sreenivasulu, K., Gangadhara, S., Venkateswarlu, P., 2017c. Bio inspired green synthesis of $\mathrm{Ni} / \mathrm{Fe}_{3} \mathrm{O}_{4}$ magnetic nanoparticles using Moringa oleifera leaves extract: a magnetically recoverable catalyst for organic dye degradation in aqueous solution. $\mathrm{J}$. Alloys. Compd. 700, 252-258. https://doi.org/10.1016/j.jallcom.2016.12.363.

Prasad, C., Yuvaraja, G., Venkateswarlu, P., 2017d. Biogenic synthesis of $\mathrm{Fe}_{3} \mathrm{O}_{4}$ magnetic nanoparticles using Pisum sativum peels extract and its effect on magnetic and Methyl orange dye degradation studies. J. Magn. Magn. Mater. 424, 376-381. https://doi.org/10.1016/j.jmmm.2016.10.084.

Radini, I.A., Hasan, N., Malik, M.A., Khan, Z., 2018. Biosynthesis of iron nanoparticles using Trigonella foenum-graecum seed extract for photocatalytic methyl orange dye degradation and antibacterial applications. J. Photochem. Photobiol. B, Biol. 183 (April), 154-163. https://doi.org/10.1016/j.jphotobiol.2018.04.01.

Rai, A., Singh, A., Ahmad, A., Sastry, M., 2006. Role of halide ions and temperature on the morphology of biologically synthesized gold nanotriangles. Langmuir 22, 736-741.

Rajiv, P., Bavadharani, B., Kumar, M.N., Vanathi, P., 2017a. Synthesis and characterization of biogenic iron oxide nanoparticles using green chemistry approach and evaluating their biological activities. Biocatal. Agric. Biotechnol. 12, 45-49. https:// doi.org/10.1016/j.bcab.2017.08.015.

Rajiv, P., Bavadharani, B., Kumar, M.N., Vanathi, P., 2017b. Synthesis and characterization of biogenic iron oxide nanoparticles using green chemistry approach and evaluating their biological activities. Biocatal. Agric. Biotechnol. 12, 45-49. https:// doi.org/10.1016/j.bcab.2017.08.015.

Raut, R.W., Mendhulkar, V.D., Kashid, S.B., 2014. Photosensitized synthesis of silver nanoparticles using Withania somnifera leaf powder and silver nitrate. J. Photochem. Photobiol. B Biol. 132, 45-55.

Rauwel, P., Küünal, S., Ferdov, S., Rauwel, E., 2015. A review on the green synthesis of silver nanoparticles and their morphologies studied via TEM. Adv. Mater. Sci. Eng. 2015. https://doi.org/10.1155/2015/682749.

Rethinasabapathy, M., Kang, S., 2017. Ternary PtRuFe nanoparticles supported N-doped graphene as an efficient bifunctional catalyst for methanol oxidation and oxygen reduction reactions. Int. J. Hydrogen Energy 42 (52), 30738-30749. https://doi.org/ 10.1016/j.ijhydene.2017.10.121.

Khaghani, S., Ghanbari, S.K., 2017. Green synthesis of Iron oxide-Palladium nanocomposites by pepper extract and its application in removing of colored pollutants from water. J. Nanostructure Chem. 7 (3), 175-182.

Saif, S., Tahir, A., Chen, Y., 2016. Green synthesis of Iron nanoparticles and their environmental applications and implications. Nanomaterials 6 (11), 209. https://doi. org/10.3390/nano6110209.

Saikia, I., Hazarika, M., Hussian, N., Das, M.R., Tamuly, C., 2017. Biogenic synthesis of $\mathrm{Fe}_{2} \mathrm{O}_{3} @ \mathrm{SiO}_{2}$ nanoparticles for ipso-hydroxylation of boronic acid in water. Tetrahedron Lett. 58 (45), 4255-4259. https://doi.org/10.1016/j.tetlet.2017.09.075.

Sajadi, S.M., Nasrollahzadeh, M., Maham, M., 2016. Aqueous extract from seeds of Silybum marianum L. as a green material for preparation of the $\mathrm{Cu} / \mathrm{Fe}_{3} \mathrm{O}_{4}$ nanoparticles: a magnetically recoverable and reusable catalyst for the reduction of nitroarenes. J. Colloid Interface Sci. 469, 93-98. https://doi.org/10.1016/j.jcis.2016. 02.009 .

Salunke, B.K., Sawant, S.S., Lee, S.I., Kim, B.S., 2016. Microorganisms as efficient biosystem for the synthesis of metal nanoparticles: current scenario and future possibilities. World J. Microbiol. Biotechnol. 32 (5). https://doi.org/10.1007/ s11274-016-2044-1.

Sanchez, L.M., Martin, D.A., Alvarez, V.A., Gonzalez, J.S., 2018. Polyacrylic acid-coated iron oxide magnetic nanoparticles: the polymer molecular weight influence. Colloids Surf. A Physicochem. Eng. Asp. 543, 28-37. https://doi.org/10.1016/j.colsurfa.2018. 01.050.

Sangami, S., Manu, B., 2017. Synthesis of Green Iron nanoparticles using Laterite and their application as a Fenton-like catalyst for the degradation of herbicide Ametryn in water. Environ. Technol. Innov. 8, 150-163. https://doi.org/10.1016/j.eti.2017.06. 003.

Saratale, R.G., Saratale, G.D., Shin, H.S., Jacob, J.M., Pugazhendhi, A., Bhaisare, M., Kumar, G., 2017. New insights on the green synthesis of metallic nanoparticles using plant and waste biomaterials: current knowledge, their agricultural and environmental applications. Environ. Sci. Pollut. Res. Int. 1-20. https://doi.org/10.1007/ s11356-017-9912-6.

Sarkar, J., Mollick, M.M.R., Chattopadhyay, D., Acharya, K., 2017. An eco-friendly route of $\gamma-\mathrm{Fe}_{2} \mathrm{O} 3$ nanoparticles formation and investigation of the mechanical properties of the HPMC- $\gamma-\mathrm{Fe}_{2} \mathrm{O} 3$ nanocomposites. Bioprocess Biosyst. Eng. 40 (3), 351-359. https://doi.org/10.1007/s00449-016-1702-x.

Sathya, K., Saravanathamizhan, R., Baskar, G., 2017a. Ultrasound assisted phytosynthesis of iron oxide nanoparticle. Ultrason. Sonochem. 39, 446-451. https://doi.org/10. 1016/j.ultsonch.2017.05.017.

Sathya, K., Saravanathamizhan, R., Baskar, G., 2017b. Ultrasound assisted phytosynthesis of iron oxide nanoparticle. Ultrason. Sonochem. 39, 446-451. https://doi.org/10. 1016/j.ultsonch.2017.05.017.

Schneider, T., Löwa, A., Karagiozov, S., Sprenger, L., Gutiérrez, L., Esposito, T., et al., 2017. Facile microwave synthesis of uniform magnetic nanoparticles with minimal sample processing. J. Magn. Magn. Mater. 421, 283-291. https://doi.org/10.1016/j. jmmm.2016.07.063.

Schröfel, A., Šafar, M., Raška, I., Shor, L.M., Kratošová, G., Šafar, I., 2014. Acta Biomaterialia Applications of biosynthesized metallic nanoparticles - a review. Acta Biomater.(June). https://doi.org/10.1016/j.actbio.2014.05.022.

Schütte, K., Barthel, J., Endres, M., Siebels, M., Smarsly, B.M., Yue, J., Janiak, C., 2017. Corrigendum to: Synthesis of Metal Nanoparticles and Metal Fluoride Nanoparticles from Metal Amidinate Precursors in 1-Butyl-3-Methylimidazolium Ionic Liquids and Propylene Carbonate (ChemistryOpen, (2017), 6, 1, (137-148), 10.1002/ open.201600105). ChemistryOpen 6 (5), 681. https://doi.org/10.1002/open. 201700139.

Sebastian, A., Nangia, A., Prasad, M.N.V., 2018. A green synthetic route to phenolics fabricated magnetite nanoparticles from coconut husk extract: implications to treat metal contaminated water and heavy metal stress in Oryza sativa L. J. Clean. Prod. 174, 355-366. https://doi.org/10.1016/j.jclepro.2017.10.343.

Shanker, U., Jassal, V., Rani, M., 2017. Green synthesis of iron hexacyanoferrate nanoparticles: potential candidate for the degradation of toxic PAHs. J. Environ. Chem. Eng. 5 (4), 4108-4120. https://doi.org/10.1016/j.jece.2017.07.042.

Sharma, G., Kumar, A., Chauhan, C., Okram, A., Sharma, S., Pathania, D., Kalia, S., 2017a. Pectin-c rosslinked -guar gum / SPION nanocomposite hydrogel for adsorption of $\mathrm{m}$ cresol and o-chlorophenol. Sustain. Chem. Pharm. 6, 96-106. https://doi.org/10. 1016/j.scp.2017.10.003.

Sharma, G., Kumar, A., Naushad, M., Kumar, A., 2018. Photoremediation of toxic dye from aqueous environment using monometallic and bimetallic quantum dots based nanocomposites. J. Clean. Prod. 172, 2919-2930. https://doi.org/10.1016/j.jclepro. 2017.11.122.

Sharma, G., Kumar, D., Kumar, A., Al-Muhtaseb, A.H., Pathania, D., Naushad, M., Mola G.T., 2017b. Revolution from monometallic to trimetallic nanoparticle composites, various synthesis methods and their applications: a review. Mater. Sci. Eng. C 71, 1216-1230. https://doi.org/10.1016/j.msec.2016.11.002.

Shukla, A.K., Iravani, S., 2017. Metallic nanoparticles: green synthesis and spectroscopic characterization. Environ. Chem. Lett. 15 (2), 223-231. https://doi.org/10.1007/ s10311-017-0618-2.

Silveira, C., Shimabuku, Q.L., Fernandes Silva, M., Bergamasco, R., 2017. Iron-oxide nanoparticles by green synthesis method using Moringa oleifera leaf extract for fluoride removal. Environ. Technol. 3330, 1-40. https://doi.org/10.1080/09593330. 2017.1369582.

Singh, K.K., Senapati, K.K., Sarma, K.C., 2017. Synthesis of superparamagnetic Fe $3 \mathrm{O}_{4}$ nanoparticles coated with green tea polyphenols and their use for removal of dye pollutant from aqueous solution. J. Environ. Chem. Eng. 5 (3), 2214-2221. https:// doi.org/10.1016/j.jece.2017.04.022.

Singh, P., Kim, Y.J., Zhang, D., Yang, D.C., 2016. Biological synthesis of nanoparticles from plants and microorganisms. Trends Biotechnol. 34 (7), 588-599. https://doi. org/10.1016/j.tibtech.2016.02.006.

Soliemanzadeh, A., Fekri, M., 2017a. Synthesis of clay-supported nanoscale zero-valent iron using green tea extract for the removal of phosphorus from aqueous solutions. Chin. J. Chem. Eng. 25 (7), 924-930. https://doi.org/10.1016/j.cjche.2016.12.006.

Soliemanzadeh, A., Fekri, M., 2017b. The application of green tea extract to prepare bentonite-supported nanoscale zero-valent iron and its performance on removal of $\mathrm{Cr}$ (VI): effect of relative parameters and soil experiments. Microporous Mesoporous Mater. 239, 60-69. https://doi.org/10.1016/j.micromeso.2016.09.050.

Stan, M., Lung, I., Soran, M., Leostean, C., Popa, A., Stefan, M., et al., 2017. Removal of antibiotics from aqueous solutions by green synthesized magnetite nanoparticles with selected agro-waste extracts. Process. Saf. Environ. Prot. 107, 357-372. https://doi. org/10.1016/j.psep.2017.03.003.

Subramaniyam, V., Subashchandrabose, S.R., Thavamani, P., Megharaj, M., Chen, Z., Naidu, R., 2015. Chlorococcum sp. MM11-a novel phyco-nanofactory for the synthesis of iron nanoparticles. J. Appl. Phycol. 27 (5), 1861-1869. https://doi.org/ 10.1007/s10811-014-0492-2. 
Thakur, V.K., Thakur, M.K., Raghavan, P., Kessler, M.R., 2014. Progress in green polymer composites from lignin for multifunctional applications: a review. ACS Sustain. Chem. Eng. 2 (5), 1072-1092. https://doi.org/10.1021/sc500087z.

Tran, Q.H., Nguyen, V.Q., Le, A.T., 2013. Silver nanoparticles:synthesis, properties, toxicology, applications and perspectives. Adv. Nat. Sci. Nanosci. Nanotechnol. 4 Article ID 033001, 2013.

Vasantharaj, S., Sathiyavimal, S., Senthilkumar, P., Lewisoscar, F., 2019. Biosynthesis of iron oxide nanoparticles using leaf extract of Ruellia tuberosa: antimicrobial properties and their applications in photocatalytic degradation. J. Photochem. Photobiol. B, Biol. 192, 74-82. https://doi.org/10.1016/j.jphotobiol.2018.12.025.

Venkateswarlu, S., Natesh Kumar, B., Prasad, C.H., Venkateswarlu, P., Jyothi, N.V.V., 2014. Bio-inspired green synthesis of $\mathrm{Fe} 3 \mathrm{O} 4$ spherical magnetic nanoparticles using Syzygium cumini seed extract. Phys. B Condens. Matter 449, 61-71. https://doi.org/ 10.1016/j.physb.2014.04.031

Wang, P., Zhang, X., Gao, S., Cheng, X., Sui, L., Xu, Y., et al., 2017. Superior acetone sensor based on single-crystalline $\alpha-\mathrm{Fe}_{2} \mathrm{O}_{3}$ mesoporous nanospheres via [C12mim] [BF4]-assistant synthesis. Sens. Actuators B Chem. 241, 967-977. https://doi.org/10. 1016/j.snb.2016.10.136.

Wang, T., Jin, X., Chen, Z., Megharaj, M., Naidu, R., 2014. Green synthesis of Fe nanoparticles using eucalyptus leaf extracts for treatment of eutrophic wastewater. Sci. Total Environ. 466-467, 210-213. https://doi.org/10.1016/j.scitotenv.2013.07.022.

Wang, X., Le, L., Alvarez, P.J.J., Li, F., Liu, K., 2015. Synthesis and characterization of green agents coated Pd / Fe bimetallic nanoparticles. J. Taiwan Inst. Chem. Eng. 50, 297-305. https://doi.org/10.1016/j.jtice.2014.12.030.

Wei, Y., Fang, Z., Zheng, L., Pokeung, E., 2017. Biosynthesized iron nanoparticles in aqueous extracts of Eichhornia crassipes and its mechanism in the hexavalent chromium removal. Appl. Surf. Sci. 399, 322-329. https://doi.org/10.1016/j.apsusc. 2016.12.090.

Wei, Y., Fang, Z., Zheng, L., Tan, L., Tsang, E.P., 2016a. Green synthesis of Fe nanoparticles using Citrus maxima peels aqueous extracts. Mater. Lett. 185, 384-386. https://doi.org/10.1016/j.matlet.2016.09.029.

Wei, Y., Fang, Z., Zheng, L., Tan, L., Tsang, E.P., 2016b. Green synthesis of Fe nanoparticles using Citrus maxima peels aqueous extracts. Mater. Lett. 185, 384-386. https://doi.org/10.1016/j.matlet.2016.09.029.

Weng, X., Guo, M., Luo, F., Chen, Z., 2017. One-step green synthesis of bimetallic Fe/Ni nanoparticles by eucalyptus leaf extract: biomolecules identification, characterization and catalytic activity. Chem. Eng. J. 308, 904-911. https://doi.org/ 10.1016/j.cej.2016.09.134.

Weng, X., Jin, X., Lin, J., Naidu, R., Chen, Z., 2016. Removal of mixed contaminants Cr (VI) and Cu(II) by green synthesized iron based nanoparticles. Ecol. Eng. 97, 32-39. https://doi.org/10.1016/j.ecoleng.2016.08.003.

Williams, M.J., Sánchez, E., Aluri, E.R., Douglas, F.J., MacLaren, D.A., Collins, O.M., et al., 2016. Microwave-assisted synthesis of highly crystalline, multifunctional iron oxide nanocomposites for imaging applications. RSC Adv. 6 (87), 83520-83528. https://doi.org/10.1039/C6RA11819D.

Wu, W., Wu, Z., Yu, T., Jiang, C., 2015. Recent progress on magnetic iron oxide nanoparticles: synthesis, surface functional strategies and biomedical applications. Sci. Technol. Adv. Mater. 16. https://doi.org/10.1088/1468-6996/16/2/023501.

Xiao, Z., Yuan, M., Yang, B., Liu, Z., Huang, J., Sun, D., 2016. Plant-mediated synthesis of highly active iron nanoparticles for $\mathrm{Cr}$ (VI) removal: investigation of the leading biomolecules. Chemosphere 150, 357-364. https://doi.org/10.1016/j.chemosphere. 2016.02.056.

Xiao, Z., Zhang, H., Xu, Y., Yuan, M., Jing, X., Huang, J., et al., 2017. Ultra-efficient removal of chromium from aqueous medium by biogenic iron based nanoparticles. Sep. Purif. Technol. 174, 466-473. https://doi.org/10.1016/j.seppur.2016.10.047.

Xin, H., Yang, X., Liu, X., Tang, X., Weng, L., Han, Y., 2016. Biosynthesis of iron nanoparticles using tie guanyin tea extract for degradation of bromothymol blue. J. Nanotechnol. 2016. https://doi.org/10.1155/2016/4059591.

Yang, F., Zhang, S., Sun, Y., Cheng, K., Li, J., Tsang, D.C.W., 2018. Fabrication and characterization of hydrophilic corn stalk biochar-supported nanoscale zero-valent iron composites for efficient metal removal. Bioresour. Technol. https://doi.org/10. 1016/j.biortech.2018.06.029.

Zhang, S., Zhang, Q., Zhang, Y., Chen, Z., Watanabe, M., Deng, Y., 2016. Beyond solvents and electrolytes: ionic liquids-based advanced functional materials. Prog. Mater. Sci. 77, 80-124. https://doi.org/10.1016/j.pmatsci.2015.10.001.

Zheng, X., He, L., Duan, Y., Jiang, X., Xiang, G., Zhao, W., Zhang, S., 2014. Poly(ionic liquid) immobilized magnetic nanoparticles as new adsorbent for extraction and enrichment of organophosphorus pesticides from tea drinks. J. Chromatogr. A 1358, 39-45. https://doi.org/10.1016/j.chroma.2014.06.078.

Zhu, F., Ma, S., Liu, T., Deng, X., 2018. Green synthesis of nano zero-valent iron / Cu by green tea to remove hexavalent chromium from groundwater. J. Clean. Prod. 174, 184-190. https://doi.org/10.1016/j.jclepro.2017.10.302. 